CHAPTER 23

\title{
TIMING IN ANIMALS: FROM THE NATURAL ENVIRONMENT TO THE LABORATORY, FROM DATA TO MODELS
}

\author{
Marco Vasconcelos, Marilia Pinheiro de Carvalho, and Armando Machado
}

The capacity to adjust to temporal regularities in the environment is widespread in the animal kingdom. Animals are able to tailor their behavior and physiology to a variety of periodic regularities spanning from very high to very low frequencies (i.e., from seconds to years).

One of the most obvious regularities is the daily light-dark cycle. An animal able to anticipate daily environmental changes and fine tune its behavior and physiology to them would certainly benefit in the struggle for survival and reproduction. Thus, from a functional perspective one would expect natural selection to have favored sensitivity to the correlates of the 2 -h rotation of the Earth. In other words, natural selection should have engendered (as it did) what are known as circadian why thms at the physiological and behavioral levels (see Volume 1, Chapter 29, this handbook). Such rhythms are generated by internal clocks set or entrained by regular environmental cues, with the daily light-dark cycle having the dominant role (e.g., Panda, Hogenesch, \& Kay, 2002; Reppert \& Weaver, 2002). Biological and social stimuli, though, may also entrain circadian rhythms (e.g., Davidson \& Menaker, 2003, Mistlberger \& Skene, 2004).

In animal research, the periodic nature of feeding activities has been given much of the spotlight.

Circadian regulated feeding was found in a variety of species including, among many others, honeybees (Apis mellifera; Beling, 1929; Frisch \& Aschoff,
1987; Pahl, Zhu, Pix, Tautz, \& Zhang, 2007), garden warblers (Sylvia borin; Biebach, Falk, \& Krebs, 1991), pigeons (Columba livia; Saksida \& Wilkie, 1994), and rats (Rattus norvegicus; Bolles \& Moot, 1973). Circadian clocks also seem to modulate sensory (e.g., Krishnan, Dryer, \& Hardin, 1999) and cognitive performance in a variety of tasks and species (e.g., Cain, Chou, \& Ralph, 2004; Kyriacou \& Hiastings, 2010), as well as a variety of physiological variables such as temperature (Refinetti \& Menaker, 1992) and heart rate (Massin, Maeyns, Withofs, Ravet, \& Gérard, 2000), to name a few.

Another periodic regularity is afforded by the $23.48^{\circ}$ axial tilt of the Earth as it makes its annual elliptical orbit around the Sun. This tilt leads to the environmental periodicities called seasons, each raising its own challenges and opportunities to animal adaptation. Here too, natural selection sculpted organisms able to adjust behaviorally and physiologically to the many season-specific ordeals, thus allowing them to cope with the annual changes (Gwinner, 2012; Lincoln, Clarke, Hut, \& Hazlerigg, 2006; Zucker, 2001). Adaptations to these longterm cycles include not only the well-known cases of hibernation (e.g., Kondo et al., 2006; Pengelley \& Asmundson, 1974), migration (e.g., Gwinner, 2001), and reproduction (e.g., Karsch, Robinson, Woodfill, \& Brown, 1989), but also, among many others, pelage growth (e.g., Martinet, MondainMonval, \& Monnerie, 1992), timing of pupation in

Preparation of this chapter was supported by Grant Nos. IF/01624/2013/CP1158/CT0012 and PTDC/MHC-PCN/3540/2012, Investigator Grant No. IF/01624/2013, and Doctoral Grant No. SFRH/BD/73875/2010 from the Portuguese Foundation for Science and Technology.

http://dx.doi.org/10.1037/XXXXX-XXX

APA Handbook of Comparative Psychology: Vol. 2. Perception, Learning, and Cognition, J. Call (Editor-in-Chief)

Copyright $\odot 2017$ by the American Psychological Association. All rights reserved. 
some insects (e.g., Nisimura \& Numata, 2001), and food intake and body condition (Loudon, 1994).

These fine tunings to the daily and annual regularities of the environment are, to some extent, unsurprising considering their ubiquity and stability, as well as their daily impact in the animals' ecosystem. Perhaps more unexpected is the animals' ability to adjust to or display temporal regularities of seemingly arbitrary durations. Periodical cicadas of the genus Magicicada (Homoptera: Cicadidae) provide one of the most fascinating examples of long temporal regularities: Every 13 or 17 years, depending on the species, they emerge from the ground, develop into adults, mate, lay eggs, and die, all within an interval of 4-6 weeks (Williams \& Simon, 1995). Most of the fascination with these long-lived insects comes from their prime-numbered life cycle and their synchronous emergence in staggering numbers (up to 3.5 million $\mathrm{ha}^{-1}$ ). Several hypotheses have been put forward to explain this behavioral synchronicity, from the avoidance of long-lived parasitoids (Lloyd \& Dybas, 1966a, 1966b) to predator avoidance (Hoppensteadt \& Keller, 1976) and hybridization avoidance (Cox \& Carlton, 1988, 1991), but the issue remains controversial (see, e.g., Grant, 2005).

What about arbitrary short durations? Do animals adjust their behavior when the environment imposes temporal regularities in the range of seconds to minutes? Animals are generally able to performan action for a specific duration; anticipate an event once a particular interval has elapsed; retrospectively judge which of two intervals was shorter; or choose which of several cues signals the shortest delay to reward. This capacity is called interval timing, or timing, and it is the main topic of this chapter.

In what follows, we briefly underscore the relevance of interval timing in the natural habitat and then focus our discussion on laboratory research. We describe the most relevant experimental procedures, the typical pattern of results obtained with them, and two of the theoretical models that have been proposed to explain such results and generate novel predictions.

\section{THE RELEVANCE OF SHORT INTERVALS}

In the natural world, animals can use a multitude of cues to regulate their behavior. The time elapsed since a particular event is one of them, but one cannot be sure whether it is indeed used or if it interacts or is even confounded with other available cues. The assumption that timing regulates some behavior in the wild is to some extent risky given the lack of controls, but the abundant evidence for timing in carefully controlled laboratory experiments mitigates the risk. Be that as it may, there are several domains of animal behavior that would ostensibly benefit from interval timing in natural circumstances.

Any animal foraging on a renewable food source faces a natural timing task. Assuming the animal is sensitive to the inter replenishment intervals, it can forage more efficiently not only by avoiding recently visited food sources but also by visiting each particular resource at or ctose to the moment of its new replenishment. This behavior is known as cropping and has been observed in a variety of species. Cody (1971), for example, observed various species of finches in the Mohave Desert moving to different foraging sites each day and revisiting each site according to its replenishing interval. Similar behaviorhas been observed in pied wagtails (Motacilla alba; Davies \& Houston, 1981) and many other species. Henderson, Hurly, Bateson, and Healy (2006) reported a particularly relevant field experiment with territorial rufous hummingbirds (Selasphorus rufus). The experimenters replenished eight artificial flowers at different intervals, four flowers $10 \mathrm{~min}$ after the bird emptied them, and the other four at 20 min after being emptied. As Figure 23.1 shows, hummingbirds matched their return visits to the refill schedules, with the frequency distributions of intervisit times peaking at the appropriate intervals.

Closely related to these examples is time-place learning (for a review, see Thorpe \& Wilkie, 2006), wherein animals change their foraging site according to predictable temporal patterns. Typical demonstrations include the anticipation of tidal rhythms by wading oystercatchers (Haematopus ostralegus) to match foraging bouts with the time mussel beds become exposed (Daan \& Koene, 1981) and the increased visits by krestels (Falco tinnunculus) to a previously seldom visited field around the time mice were now regularly released (Rijnsdorp, Daan, \& Dijkstra, 1981). This type of temporal regulation 


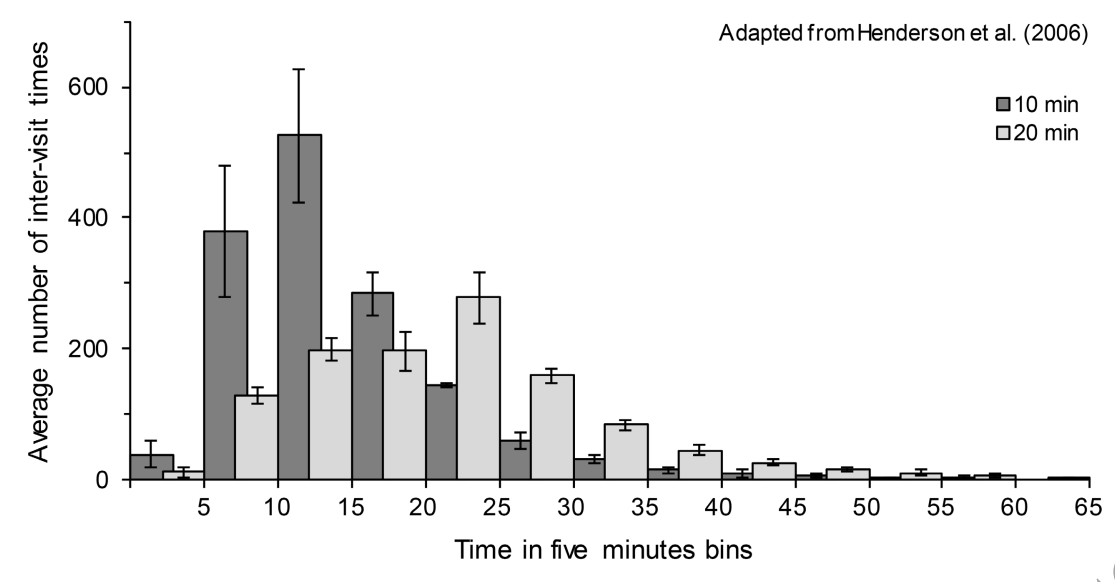

FIGURE 23.1. Average frequency distributions of intervisit intervals ( $\mathrm{n}=3$ rufous hummingbirds). From "Timing in Free-Living Rufous Hummingbirds, Selasphorus rufus," by J. Henderson, T. A. Hurly, M. Bateson, and S. D. Healy, 2006, Current Biology, 16, p. 513. Copyright 2006 by Elsevier. Adapted with permission.

has been observed in many other species, including garden warblers (Biebach et al., 1991; Biebach, Gordijn, \& Krebs, 1989), starlings (Sturnus vulgaris; Wenger, Biebach, \& Krebs, 1991), eight small passerine species (Stein, 1951), honeybees (e.g., Beling, 1929; Wahl, 1932), a variety of fish (Barreto, Rodrigues, Luchiari, \& Delicio, 2006; Delicio \& Barreto, 2008), rats (e.g., Carr, Tan, \& Wilkie, 1999; Carr \& Wilkie, 1997; Pizzo \& Crystal, 2002; Thorpe, Hallett, \& Wilkie, 2007; Thorpe \& Wilkie, 2005), and pigeons (e.g., Saksida \&Wilkie, 1994; Wilkie, Saksida, Samson, \& Lee, \$994).

Many of these time-place situlations are amenable to circadian regulation, butinterval timing is also involved in some of them, either exclusively (Wilkie et al., 1994) or in combination with circadian timing (e.g., Pizzo \& Crystal, 2002). The length of the interval seems to be a key factor determining which timing mechanisms is deployed: Interval timing for relatively short durations and circadian timing for longer durations' (Wilkie et al., 1994). Overall, time-place léarning tasks may be solved on the basis of circadian and/or interval timing, depending for example on the discriminability of the time intervals, but also on many other relevant cues (e.g., in the oystercatchers' case, multiple visual cues that correlate with tides; see Crystal, 2006; Thorpe \& Wilkie, 2006).

Optimal foraging theory (Stephens \& Krebs, 1986) also presupposes suitable temporal perception Assuming that resource distributions are unstable, thus precluding the evolution of stable strategies across generations, animals must develop foraging strategies on the basis of experlenced distributions (McNamara \& Houston, 1985). One of the best studied foraging scenarios is the marginal value theorem (MVT; Charnov, 1976; Parker \& Stuart, 1976) as applied to central place foraging. Because the benefit of foraging in a particular patch increases less than linearly (the more food is found, the harder it is to obtain the next piece of food), at some point the local capture rate is not profitable enough compared with the average rate of the environment. The question then becomes, when should the animal abandon the patch? The answer is at the precise time when the local rate equals the overall rate (for a detailed treatment, see Chapter 14, this volume). Importantly, as the average travel time to a patch decreases so should the optimal residence time because less time is spent traveling the higher the capture rate. To our knowledge this prediction was met in every test (e.g., Kacelnik, 1984).

It should be clear from the previous discussion that the MVT requires sensitivity to various time intervals such as travel time and interprey capture. In a laboratory task emulating the less than linear increase in benefit, Brunner, Kacelnik, and Gibbon (1992; see also Kacelnik \& Brunner, 2002) showed 
that starlings seem to use interval timing to solve the task.

Communication is also, by definition, temporally structured: The sender must be able to transmit a message composed of signals in a particular sequence and duration such that the receiver is able to understand it. Songbirds, for example, learn songs and sometimes specific dialects by listening to other individuals (conspecifics or not; Baptista \& Morton, 1988; Beecher \& Brenowitz, 2005; Beecher, Campbell, \& Stoddard, 1994; Marler \& Tamura, 1964; see also Volume 1, Chapters 26 and 30, this handbook). This requires learning the frequencies and durations of each song component. Similarly, a variety of insect species including brush-legged wolf spiders (Schizocosa ocreata; Gibson \& Uetz, 2008), field crickets (Teleogryllus oceanicus; Rebar, Bailey, \& Zuk, 2009), and fireflies (Coleoptera: Lampyridae; Lewis \& Cratsley, 2008) extract information used in mate choice from the interpulse intervals and other temporal properties of the signals sent by potential partners.

This small tour illustrates the adaptive contributions that interval timing may have in countless naturally occurring behaviors. But to understand the precise properties of interval timing, understood as the control of behavior by arbitrary periodicities shorter than $24 \mathrm{~h}$, we need to resort to the controlled conditions of the laboratory.

\section{THE PSYCHOPHYSICS OF TIME: PROCEDURES AND DATA}

The control of behavior by relatively short intervals has been evident since early laboratory experiments in classical and operant conditioning. Even though we will focus our discussion in operant preparations, some of the first examples were reported by Pavlov (1927). For example, when a delay conditioning procedure is used (i.e., the learned cue, the conditional stimulus, is presented on its own and ends with the presentation of the biologically relevant stimulus, the unconditional stimulus), animals show a conditioned response only toward the end of the interval. This phenomenon is called inhibition of delay and suggests the animal is timing the learned cue.
The field of interval timing has produced some of the most elegant experimental procedures and explanatory models in the field of experimental psychology. We describe next some of the typical procedures, including concurrent timing tasks, in which animals respond as the critical interval elapses (e.g., fixed-interval schedule, mixed fixedinterval schedules, peak procedure) and retrospective timing tasks in which the animal responds only after an interval ends (e.g., temporal generalization procedure, bisection task). We will then use some of them to illustrate how the models handle different tasks.

\section{The Fixed-Interval Schedule and the Mixed Fixed-Interval Schedule} The operant equivalent of the delay conditioning procedure that led to the discovery of inhibition of delay is the fixed-interval (FI) reinforcement schedule. In a FI T-s schedule, a time maker such as the previous reinforcer or the onset of a tone or a light initiates the to-be-timed interval. Responses during the T-s interval are not reinforced and the first response after T-s elapse is reinforced and terminates the trial.

Clearly, optimal performance in such a schedule requires a single response immediately after T-s have elapsed. But as we will see in the following sections, timing mechanisms are not sufficiently accurate for such a pattern of behavior to emerge. Instead, as training proceeds, animals start to temporally differentiate their behavior, with little or no responding early in the interval, followed by one of two possible patterns: (a) a gradual acceleration of responding peaking near the end of the interval (the scallop pattern; Dews, 1978) or (b) a sudden transition from a low rate of responding to a high and constant rate that persists until the end of the interval (the break-and-run pattern; Schneider, 1969). Which pattern is observed seems to depend on the length of the interval, with longer intervals engendering the former. Regardless of the pattern observed on each trial, when a number of such trials are aggregated, the response-rate function resembles and is well fitted by the left limb of a normal distribution. Figures 23.2a and 23.2b show data from pigeons and rats trained in FIs ranging from $30 \mathrm{~s}$ to 
$300 \mathrm{~s}$ and from $3 \mathrm{~h}$ to $7 \mathrm{~h}$, respectively. For a comparative analysis of fixed-interval performance in several species, including pigeons, rats, woodmice (Apodemus sylvaticus), domestic turtle doves (Streptopelia risoria), tilapia (Sarotherodon niloticus), and freshwater turtles (Pseudemys scripta elegans), see Lejeune and Wearden (1991). Boisvert and Sherry (2006) reported similar findings in an invertebrate, the bumble bee (Bombus impatiens).

Through the years, a flurry of research has attempted to identify the variables that influence responding in FI schedules, including the interval length, the amount of training, and the magnitude of the reward on several dependent variables such as the duration of the initial pause, the overall pattern of responding (break-and-run versus scallop), and the rate of responding, among others (e.g., Dews, 1978; Guilhardi \& Church, 2004; Lejeune \& Wearden, 1991; Lowe \& Harzem, 1977; Lowe, Harzem, \& Spencer, 1979; Richelle \& Lejeune, 1980; Schneider, 1969; Wynne \& Staddon, 1988). Undoubtedly, the most relevant finding was that the response rate functions superimpose when both axes are scaled; the $x$-axis with respect to $\mathrm{T}$ and the $y$-axis with respect to the maximum response rate observed during the interval (e.g., Dews, 1970). Figures 23.2c and 23.2d showexamples of superimposition of rate functions. Superimposition across different FI values means that, regardless of the absolute FI value, the same proportion of the maximum response rate occurs at a particular proportion of the interval. Known as the scalar
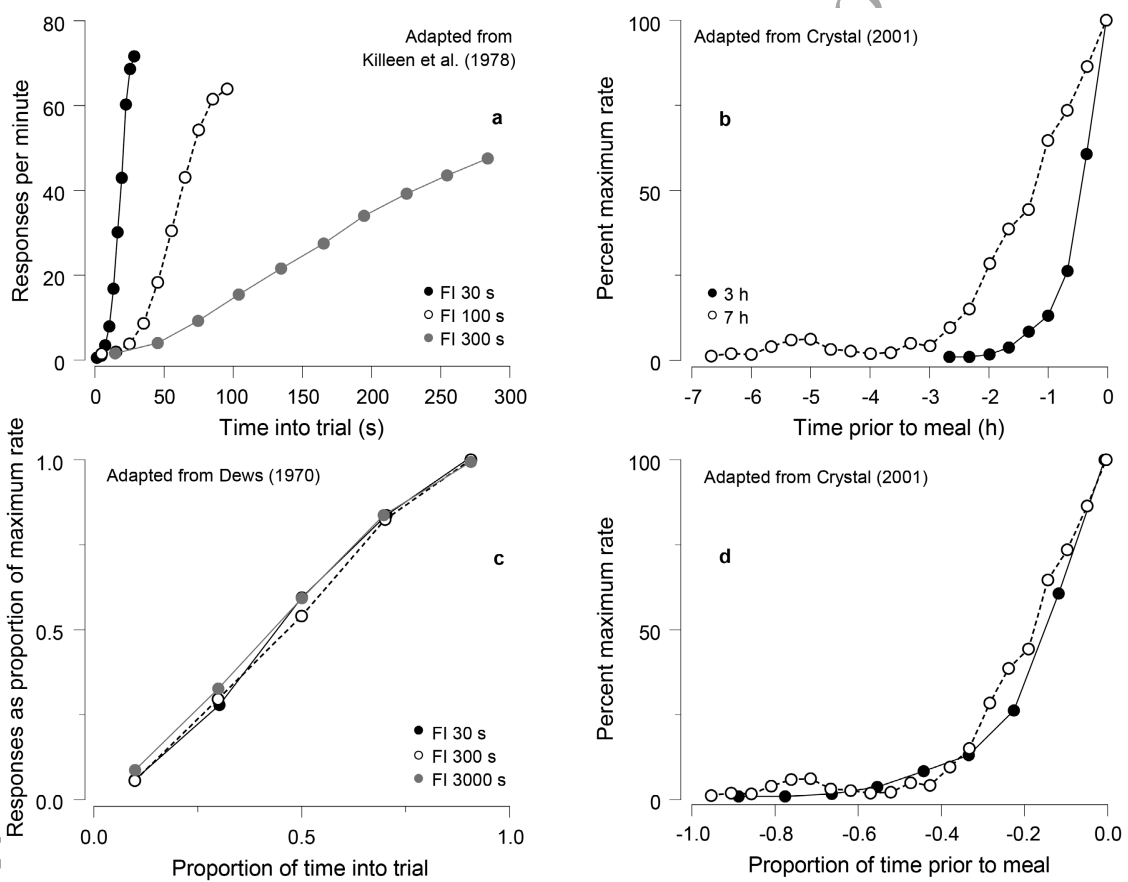

FIGURE 23.2. Average response rates in different FI schedules as a function of time into the trial. (a) Average response rates $(n=3$ pigeons) in three FI schedules. Adapted from "Arousal: Its Genesis and Manifestation as Response Rate," by P. R. Killeen, S. J. Hanson, and S. R. Osborne, 1978, Psychological Review, 85, p. 574. Copyright 1978 by the American Psychological Association. (b) Average response rates ( $\mathrm{n}=6$ rats) in two modified FI schedules. Adapted from "Circadian Time Perception," by J. D. Crystal, 2001, Journal of Experimental Psychology: Animal Behavior Processes, 27, p. 70. Copyright 2001 by the American Psychological Association. (c) The superposition of data from three FI schedules as predicted by the scalar property. From The Theory of Reinforcement Schedules (p. 48), by W. N. Schoenfeld, 1970, New York, NY: Appleton-CenturyCrofts. Copyright 1970 by Appleton-Century-Crofts. Adapted with permission. (d) Data from (b) plotted as relative response rate as a function of relative time. 
property, this is the quasiuniversal hallmark of short interval time perception (for discussions of its violation, see Lejeune \& Wearden, 2006; Staddon \& Cerutti, 2003; Zeiler \& Powell, 1994).

To observe the scalar property, the standard deviation of the measured behavioral variable should increase linearly with its mean, yielding a near-constant coefficient of variation. If we define timing accuracy by the coefficient of variation, then the scalar property means that timing accuracy remains constant across different intervals. The scalar property is thus the equivalent of Weber's law in the time domain (see Chapters 1 and 16, this volume). Given its ubiquity, the scalar property has imposed a significant constraint to timing theories as it must be accommodated in some fashion. This property gives the name to one of such theories, the scalar expectancy theory (Gibbon, 1977, 1991; Gibbon, Church, \& Meck, 1984).

One issue that remains poorly understood is the effect of reinforcement at $\mathrm{T}$ on durations longer than $\mathrm{T}$. The few studies and observations that omitted the reinforcer and prolonged the interval indicate that the response rate either remains high (Ferster \& Skinner, 1957; Machado \& Cevik, 1998; Monteiro \& Machado, 2009) or oscillates between pauses and periods of responding (Crystal \& Baramidze, 2007. Kirkpatrick-Steger, Miller, Betti, \& Wasserman, 1996; Machado \& Cevik, 1998; Monteiro \& Machado, 2009), depending on how long the interyal is prolonged. In other words, reinforcement at $\mathrm{T}$ seems to have different effects on responding before and after $\mathrm{T}$. This asymmetry chalfenges the inference that because the maximum response rate occurs at $\mathrm{T}$, the animal is timing the interval. Hence some researchers prefer to analyze the time of the first response (known as waiting time) in FI schedules. The general finding is, however, that the steady-state duration of the average waiting time is indeed a linear function of the programmed FI (Catania, 1970; Ferster \& Skinner, 1957; Richelle \& Lejeune, 1980; Wynne \& Staddon, 1988).

The FI schedule is also often used in mixed schedules. In one of the simplest, the mixed FI $T_{1^{-}}$ FI $T_{2}$ schedule, on a proportion of trials, $p$, the first response after $T_{1} s$ have elapsed is reinforced; on the remaining trials, reinforcement is contingent on the first response after $T_{2} s$ have elapsed, with $T_{1}<$ $\mathrm{T}_{2}$ (Catania \& Reynolds, 1968; Ferster \& Skinner, 1957; Leak \& Gibbon, 1995; Lima, 2010; Whitaker, Lowe, \& Wearden, 2003, 2008). Because both FIs are signaled by the same cue, when the FI $T_{1}$ is in effect, the average response pattern is similar to the one observed in the single FI schedule of reinforcement. However, when the FI $\mathrm{T}_{2}$ is in effect, a bimodal response pattern emerges. Figure 23.3 shows the response rate function obtained by Whitaker et al. (2003) using a mixed FI 30 s-FI 240 s. The function shows an increase in response rate foward a peak located close to $30 \mathrm{~s}$ into the trial, a subsequent decrease to low levels, and a final ipcrease reaching a peak at $240 \mathrm{~s}$.

The mixed FI-FI schedule of reinforcement is particularly important to understand timing mechanisms, for it shows that animals are able to learn to time two intervals to food signaled by the same cue. Moreover, some models assume the existence of separate memory stores for each reinforced interval (i. C, concentrated memories), whereas others assume that temporal memories are distributed. The response patterns observed in the longer components of a mixed FI-FI schedule are consistent with the latter and raise serious challenges to the former.

\section{The Peak Procedure}

Intimately related to the FI schedule, the peak procedure (Catania, 1970; S. Roberts, 1981) allows us to directly assess temporal memories. In some cases, it also illustrates the ability of animals to time at least two different intermixed durations sometimes signaled via different sensory modalities (e.g., S. Roberts, 1981). Formally a mixed schedule, the peak procedure is composed of two types of trials signaled by the same cue: regular FI T-s training trials interspersed with longer trials (say 3T-s) ending without reinforcement, known as peak or empty trials. Typically, after sufficient training, the average response rates on peak trials increase from $t=0$ to $\mathrm{t}=\mathrm{T}$ and then decreases again as $\mathrm{t}$ surpasses $\mathrm{T}$. Figures $23.4 \mathrm{a}$ and $23.4 \mathrm{~b}$ show average response rates from rats and humans in peak trials. As for relatively short FIs, these smooth functions are usually an averaging artifact, given that performance on individual peak trials usually follows a break-run-break 


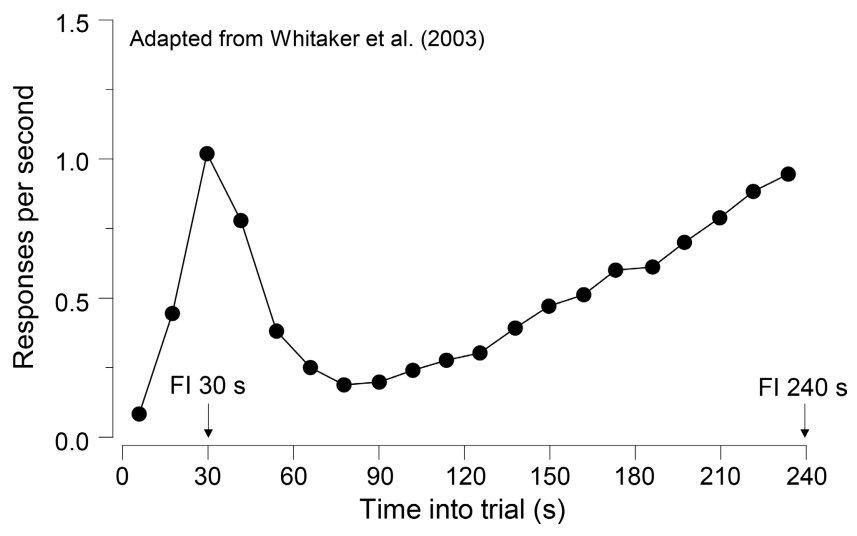

FIGURE 23.3. Average response rate as a function of time into the trial in a mixed FI 30-FI 240 s schedule ( $\mathrm{n}=4$ rats). Adapted from "Multiple-Interval Timing in Rats: Performance on Two-Valued Mixed Fixed-Interval Schedules," by S. Whitaker, C. F. Lowe, and J. H. Wearden, 2003, Journal of Experimental Psychology: Animal Behavior Processes, 29, p. 280. Copyright 2003 by the American Psychological Association.

pattern (e.g., Cheng \& Westwood, 1993; Cheng, Westwood, \& Crystal, 1993; Church, Meck, \& Gibbon, 1994; Gibbon \& Church, 1990, 1992; Zeiler \& Powell, 1994).

The response rate function typically observed in peak trials has been extensively studied, including the location of its mode (peak time), the height at the mode (peak rate), its symmetry around T, how it changes with different time markers, and how it evolves throughout training (e.g. Balci et al., 2009; Gibbon et al., 1984; Kaiser, 2008; S. Roberts, 1981, 1998; W. A. Roberts, Cheng, \& Cohen, 1989). Still other studies have examined the effects of sudden interruptions of the stimulus signaling trial onset (e.g., Cabeza de Vaca, Brown, \& Hemmes, 1994; Kaiser, Zentalt, \& Neiman, 2002; S. Roberts, 1981, 1998). When relatively long empty trials are used sometimes response rate increases again toward the end of the trials (e.g., Kaiser, 2008; W. A. Roberts et al., 1989) and may even show a cyclic pattern Cerystal \& Baramidze, 2007; Kirkpatrick-Steger et al., 1996; Machado \& Cevik, 1998; Monteiro \& Machado, 2009). But for our purposes, two findings are particularly noteworthy. First, as for the fixed interval schedules, the curves for different values of $\mathrm{T}$ superimpose when plotted in a common scale (i.e., they follow the scalar property); Figures $23.4 \mathrm{c}$ and $23.4 \mathrm{~d}$ show the same data of Figures 23.4a and $234 \mathrm{~b}$ plotted in scaled axes. Second, to observe the decrease in response rate for intervals longer than $\mathrm{T}$, the animal must repeatedly experience those intervals in extinction.

\section{The Temporal Generalization Procedure}

The temporal generalization procedure is a conditional discrimination task in which the sample duration signals whether a response will be reinforced. In its simple form, it is the retrospective analog of the FI schedule: Each training trial involves the presentation of a stimulus with one of two possible durations, $\mathrm{T}_{\mathrm{S}}$ or $\mathrm{T}$ seconds, with $\mathrm{T}_{\mathrm{S}}<\mathrm{T}$. At the end of the stimulus, a response key is illuminated or a lever is inserted to allow the animal to respond, but only responses that follow $\mathrm{T}$ are reinforced; those that follow $\mathrm{T}_{\mathrm{S}}$ are not. After learning this discrimination, unreinforced generalization trials with intermediate durations are interspersed amongst the training trials. Typically, the response rate or probability increases from $T_{S}$ to $T$, with the gradients obtained with different values of $\mathrm{T}$ following the scalar property.

If instead of two, the stimulus has three possible durations $\left(T_{S}, T\right.$, and $T_{L}$; with $\left.T_{S}<T<T_{L}\right)$ and responses are reinforced only after $\mathrm{T}$, we obtain the 

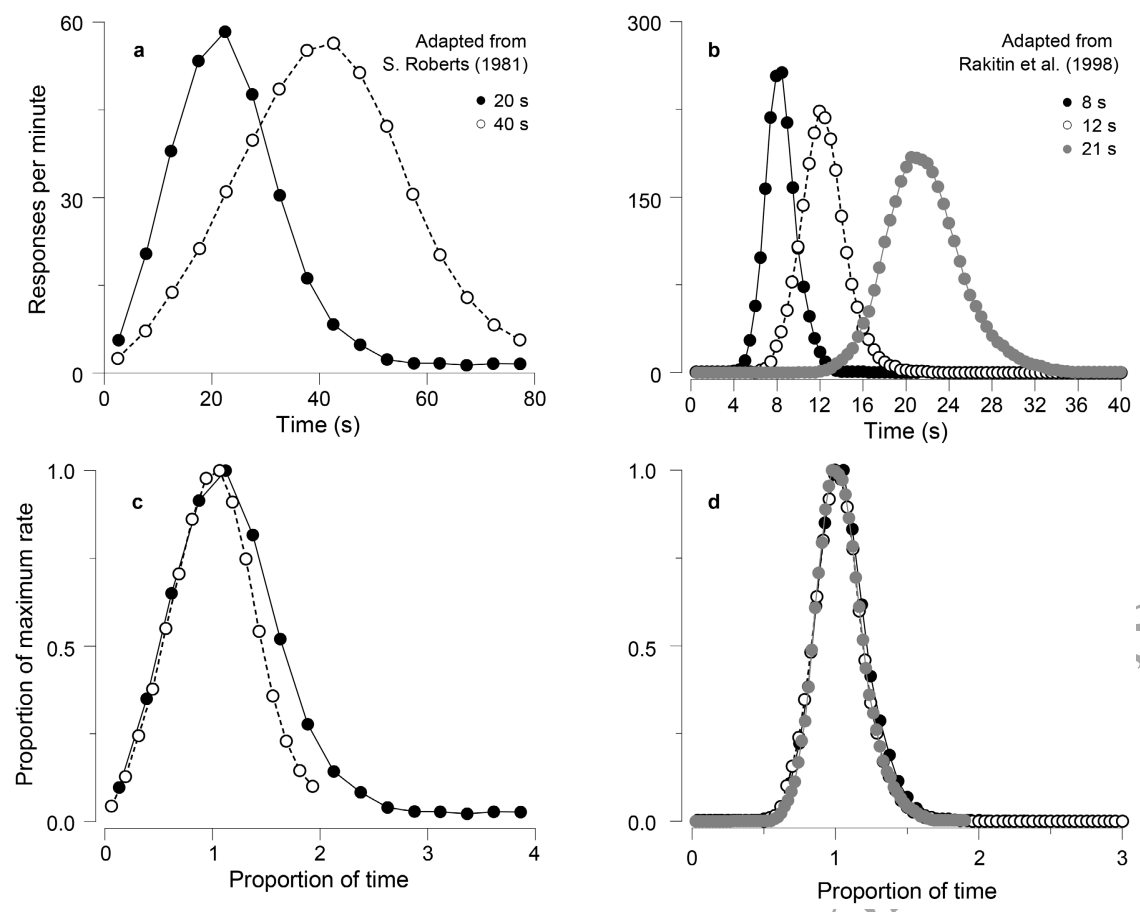

FIGURE 23.4. Average response rates as a function of time into the trial in peak trials. (a) Average response rates $(n=10$ rats) in peak trials (the corresponding FIs were $20 \mathrm{~s}$ and $40 \mathrm{~s}$ ). Adapted from Isolation of an Internal Clock," by S. Roberts, 1981, Journal of Experimental Psychology: Animal Behavior Processes, 7, p. 245. Copyright 1981,by the American Psychological Association. (b) Average response rates ( $n=7$ humans) in peak trials for participants tested with $8 \mathrm{~s}, 12 \mathrm{~s}$, and $21 \mathrm{~s} \mathrm{signal}$ durations. Adapted from "Scalar Expectancy Theory and Peak-Interval Timing in Humans," by B. C. Rakitin, J. Gibbon, T. B. Penney, C.Malapani, S. C. Hinton, and W. H. Meck, 1998, Journal of Experimental Psychology: Animal Behavior Processes, 24, p. 21. Copyright 1998 by the American Psychological Association. (c) Data from (a) plotted as relative response rate as a function of relative time. (d) Data from (b) plotted as relative response rate as a function of relative time.

retrospective timing task equivalent to the peak procedure. Because now theamimal experiences reinforcement at $\mathrm{T}$ and extinction at shorter and longer intervals, the gradient becomes Gaussianlike, peaking a $\mathrm{T}$. Also, the longer $\mathrm{T}$ is, the broader the generalization gradients are and, when different values of T are compared, these gradients conform to the scalar property, superimposing when plotted withrescaled axes. Figures 23.5a and 23.5b show the response probability functions obtained by Church and Gibbon (1982) with $\mathrm{T}=2$ and $4 \mathrm{~s}, \mathrm{~T}_{\mathrm{S}}=0.8 \mathrm{~s}$, and $\mathrm{T}_{\mathrm{L}}=7.2 \mathrm{~s}$. As in previous procedures, the curves superimpose in relative time (Figure 23.5c).

One outstanding issue concerns the shape of the generalization gradient outside the trained range.
Few studies have analyzed systematically the issue with durations shorter than $T_{S}$ or longer than $T_{L}$ (see Church \& Gibbon, 1982), but the issue is theoretically relevant given that different timing models either predict or assume particular patterns outside the experienced ranges.

\section{The Bisection Task}

The bisection task is one of the procedures most extensively used to understand timing in general and the properties of the generalization gradients in particular. In this task, a trial begins with one of two samples differing only in duration: the short sample, $S_{S}$ (e.g., a 2 s light or tone), or the long sample, $S_{L}$ (e.g., an 8 s light or tone). After 

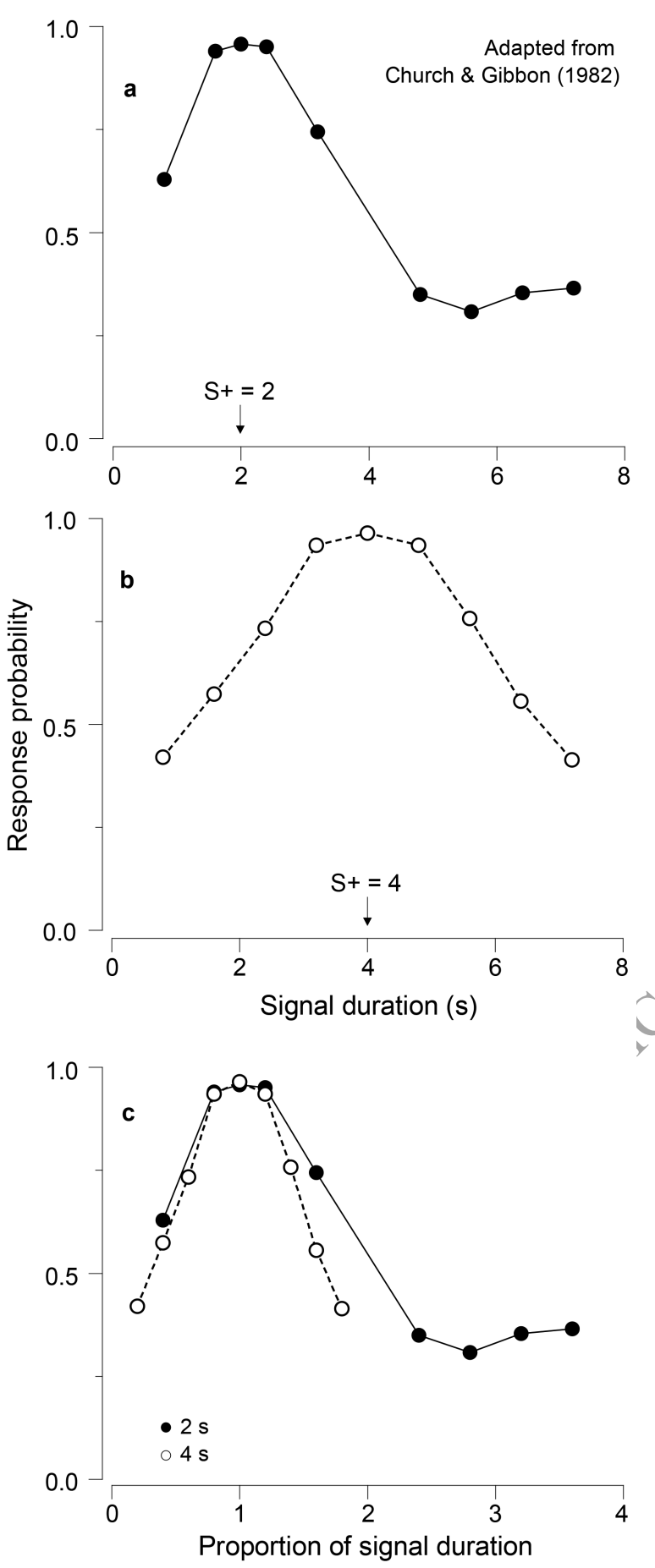

FIGURE 23.5. Median response probabilities as a function of signal duration. Reinforced durations were (a) $2 \mathrm{~s}(\mathrm{n}=7$ rats) and (b) $4 \mathrm{~s}(\mathrm{n}=10$ rats). (d) Data from (a) and (b) plotted as relative response rate as a function of relative time. Adapted from "Temporal Generalization," by R. M. Church and J. Gibbon, 1982, Journal of Experimental Psychology: Animal Behavior Processes, 8, p. 172. Copyright 1982 by the American Psychological Association. the sample, two manipulanda are simultaneously made available - two levers may slide into the operant chamber when studying rats or two response keys may be illuminated when studying birds. For simplicity, we refer to responses on these manipulanda as $R_{1}$ and $R_{2}$. The task of the subjects is to learn an arbitrary mapping. For example, choices of $R_{1}$ following $S_{S}$ and of $R_{2}$ following $S_{L}$ are reinforced, but not otherwise. Once they learn this task, the experimenter presents new samples of intermediate durations and measures the choices of, say, $R_{2}$. The function relating the proportion of $R_{2}$ responses to the sample duration is the psychometric function. Figure 23.6a shows typical psychometric functions from the seminal work of Church and Deluty (1977).

In this task animals are required to classify the just experienced interval (the sample) as relatively short or long. As Figure 23.6a suggests, the transition from a short to a long classification is rather smooth, not abrupt. In effect, the typical gradient is ogival, with few or no long responses at $S_{S}$ and reaching its maximum at $S_{L}$. Of particular interest is the duration at which they choose $\mathrm{R}_{1}$ and $\mathrm{R}_{2}$ equally often, called the point of subjective equality (PSE) or the bisection point, for it is interpreted as the duration perceived as halfway between the short and the long samples. The PSE tends to be at the geometric mean of the trained durations $\left(\mathrm{GM}=\sqrt{ }\left(\mathrm{S}_{\mathrm{S}}{ }^{*} \mathrm{~S}_{\mathrm{L}}\right)\right.$; Catania, 1970; Church \& Deluty, 1977; Platt $\&$ Davis, 1983; Stubbs, 1976). Moreover, as Figure 23.6b illustrates, gradients obtained with sample pairs with the same ratio (e.g., $S_{\mathrm{S} 1}=1$ vs. $S_{\mathrm{L} 1}=4, S_{\mathrm{S} 2}=2$ vs. $S_{\mathrm{L} 2}=8$, and $\mathrm{S}_{\mathrm{S} 3}=4$ vs. $\mathrm{S}_{\mathrm{L} 3}=16$ ), superimpose when plotted in relative time (e.g., test duration / short duration).

\section{THEORIES OF INTERVAL TIMING}

The field of interval timing has been a vibrant area of research for the last 40 years, yielding a plethora of research findings to which the previous section can barely do justice. The empirical developments were accompanied by hefty advancements on the theoretical front. What are the mechanisms underlying 

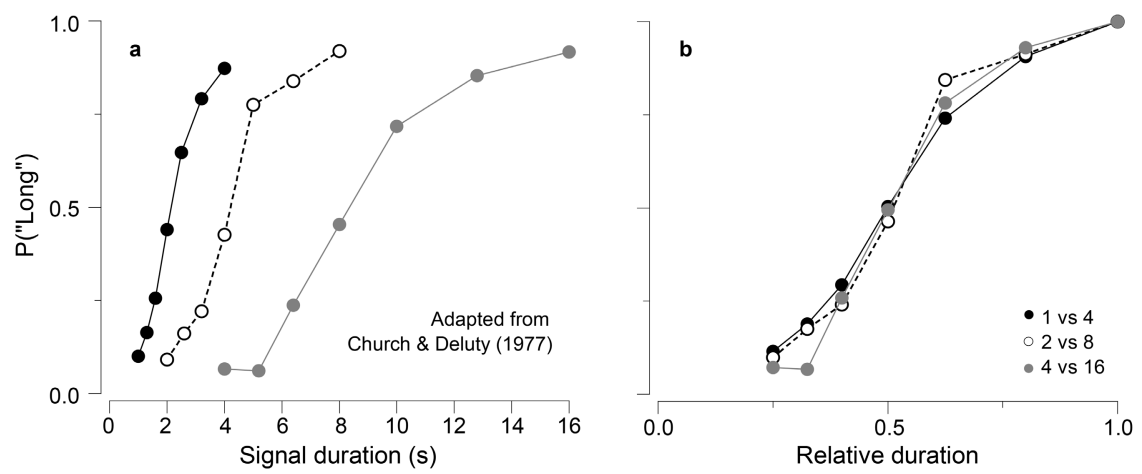

FIGURE 23.6. Temporal generalization gradients obtained in three bisection tasks ( $\mathrm{n}=8$ rats). (a) One versus four samples, two versus eight samples, and four versus 16 samples. (b) Data from (a) plotted as relative response rate as a function of relative time. Adapted from "Bisection of Temporal Intervals," by R. M. Church and M. Z. Deluty, 1977, Journal of Experimental Psychology: Animal Behavior Processes, 3, p. 220. Copyright 1977 by the American Psychological Association.

interval timing? How do those mechanisms engender Weber's law in the time domain (i.e., the scalar property)? These are two of the unavoidable questions that any theory of timing must tackle. We will focus our discussion in two models: the scalar expectancy theory (SET; e.g., Gibbon, 1977, 1991; Gibbon \& Church, 1984; Gibbon et al., 1984) and the learning-to-time model (LeT; Machado, 1997; Machado, Malheiro, \& Erlhagen, 2009). The former, a cognitive, information processing model, is arguably the most influential model of animal@nd human timing. The latter emerged from the behaviorist tradition and has proved to have broadgenerality. Many other models could be discussed; a non-exhaustive list includes the multiple oscillator theory of timing (Church \& Broadbent, 1990; see also Gallistel, 1990), the behavioral economic model of timing (Jozefowiez, Staddon, \& Cerutti, 2009), the behavioral theory of timing (Killeen \& Fetterman, 1988), packet theory (Kirkpatrick, 2002) and its modified version, modular theory of learning (Guilhardi, Yi, \& Church, 2007), the multiple-time-scale timing model (Staddon \& Higa, 1999), the spectral model (Grossberg \& Schmajuk, 1989), the diffusion model (Staddon \& Higa, 1991), and the active time model (Dragoi, Staddon, Palmer, \& Buhusi, 2003) among numerous others, some neurobiologically inspired. We focus our attention on only two, not only in the interest of space but also for theoretical reasons: SET is intuitively clear at first glance and highly influential whereas. $\mathrm{L}$ et proposes entirely different timing processes that has been studied extensively in the laboratory.

\section{The Scalar Expectancy Theory}

SET (e.g., Gibbon, 1977, 1991; Gibbon \& Church, 1984; Gibbon et al., 1984) is unquestionably a hallmark in our understanding of timing processes. It has inspired highly creative research and several generations of researchers as well as alternative approaches from those disagreeing with its assumptions or unease with its inconsistencies.

SET is a steady-state pacemaker-accumulator model with the structure shown in Figure 23.7a: A pacemaker generates pulses at a high rate, an accumulator adds the pulses when a switch is closed, a long-term memory store saves the counts from the accumulator at the end of each reinforced interval, and a comparator keeps track of the relative discrepancy between current (i.e., accumulator) time and target (i.e., memory) time. When the discrepancy is small enough, the animal starts responding.

It is known that animals' temporal judgments vary from trial to trial and that such judgments usually follow the scalar property. This implies that the timing mechanism must have at least one source of variance. For SET, variance can arise at the clock, the long-term memory, the comparator, 

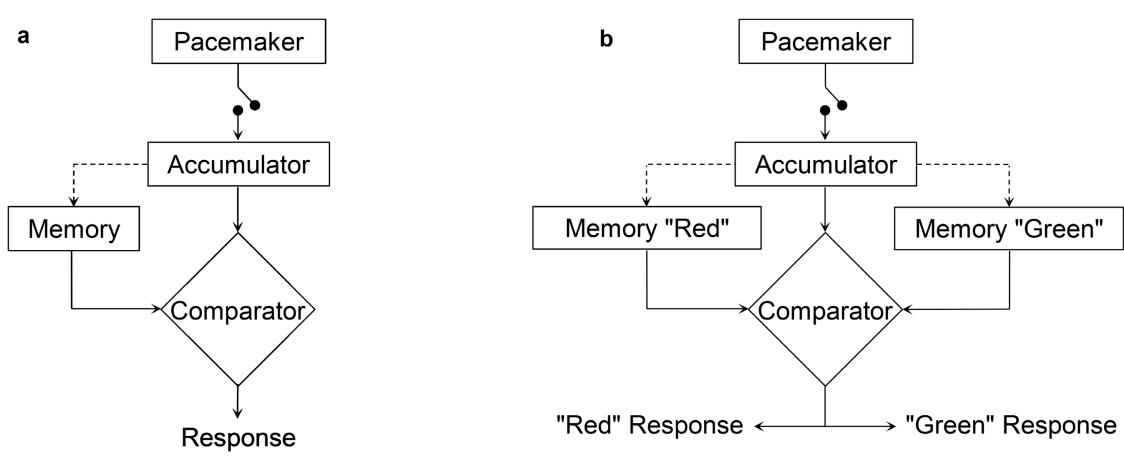

FIGURE 23.7. The structure of SET. A pacemaker generates pulses which are added to an accumulator and stored in one or more long-term memories stores at the end of the to-be-timed interval (dashed lines). The animal compares the number of pulses currently in the accumulator with samples extracted from the memories to decide when and where to respond. (a) In FI schedules, only one long-term memory store is formed. (b) In the bisection procedure, two long-term memories are formed.

or the switch latency. The pacemaker is usually conceived of as a Poisson emitter, that is, a device that generates pulses at a constant rate on average, but random, exponentially distributed interpulse intervals (Gibbon, 1977, 1992). Mathematically, a Poisson timer leads to the opposite of what is usually seen, relatively more accurate timing with larger intervals because, in Poisson processes, the variance (not the standard deviation) increases proportionally with the mean, and the coefficient of variation decreases instead of remaining roughly constant. SET has addressed this is@e in several ways, but typically it is assumed that the pacemaker emits pulses at a rate that remains constant within a trial but varies from trial to trial according to a normally distributed random variable (Gibbon et al., 1984). This generates scalar variance. Still within the efock subsystem, the switch may have variable tatencies to close and open thus adding variability to the system, but such variability shouldbe independent of the stimulus duration.

Long-term memory can also introduce variability at the moment of storage and retrieval. For example, is has been assumed that under some circumstances the counts in the accumulator are multiplied by a Gaussian random variable, $k$, when transferred to long-term memory. Finally, variance can also arise in the decision phase if we assume that the point at which the relative discrepancy between elapsed and target time is small enough varies from trial to trial (for a detailed discussion of sources of variance, see Gibbon, 1992; Gibbon et al., 1984).

To grasp the dynamics of SET, we will assume only one source of variance, that of the pacemaker, withits rate varying from trial to trial according to a normal random variable. Consider, for instance, a FI $10 \mathrm{~s}$. At the onset of a to-be-timed stimulus four important events occur: (1) one sample is drawn from a normal distribution determining the pacemaker rate, $\lambda ;$ (2) the accumulator is reset to 0 ; (3) the switch is closed and the pulses from the pacemaker start flowing into the accumulator, the accumulator then tracks the duration of the signal via the number of pulses it contains, and; (4) a sample from the long-term memory store is retrieved. Because this is a steady-state model, it is assumed that this store is already populated with previously reinforced subjective durations. As time elapses, the comparator continuously compares the elapsed time (i.e., number of pulses in the accumulator) with the remembered time. When the relative discrepancy between the two is lower than a given decision threshold, $b$, the animal starts responding at a constant rate until the end of the trial. The typical decision rule for a FI schedule is

$$
\frac{N-\lambda t}{N}<b
$$

where $N$ is the number of pulses in the sample extracted from long-term memory, $\lambda$ is the rate of the pacemaker in the trial and $t$ is the elapsed 
time ( $\lambda t$ is therefore the current number of pulses in the accumulator), and $b$ is the threshold value. This mechanism generates the aforementioned break-and-run pattern. Finally, when the signal terminates and the response is reinforced, the switch opens and the number of pulses in the accumulator is transferred to long-term memory.

The pacemaker rate and the sample extracted from long-term memory will almost certainly be different on different trials, and therefore the moment the relative discrepancy falls below the threshold will also vary across trials. The effect of this variation are shifted break-and-run patterns that, when averaged, yield a smooth sigmoid response rate function similar to the average data shown in Figures 23.2a and 23.2b. Figure 23.8 illustrates the dynamics of a FI trial according to SET.

The extension of SET to the peak procedure is straightforward. At stimulus onset on a given peak trial, a random sample sets the pacemaker rate $(\lambda)$, the switch is closed allowing the pulses to be transferred to the accumulator and a sample from long-term memory is retrieved. As the value in the accumulator increases, the relative discrepancy between the number in the accumulator and the number retrieved from memory decreases. When
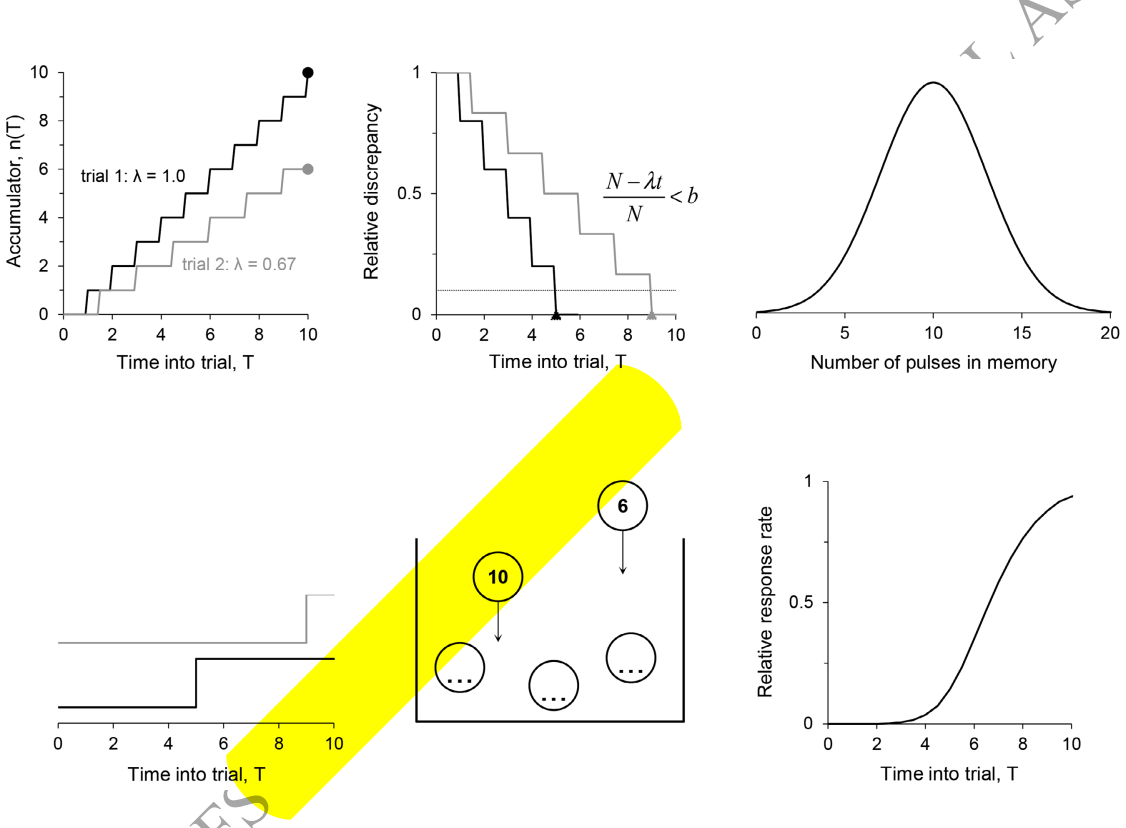

FIGURE 23.8. The dynamics of SET in a FI $10 \mathrm{~s}$ schedule. (a) As time into the trial elapses, the number of pulses in the accumulator increases at a rate $\lambda$ pulses. Two trials are shown, one with $\lambda=1.0$ and the other with $\lambda=.67$, with $\lambda$ sampled at the beginning of each trial from a normal distribution. (b) To decide when to respond, the animal compares at each moment the number of pulses in the accumulator $(\lambda t)$ with the sample extracted from long-term memory $(\mathrm{N})$. When the relative discrepancy between the two crosses the threshold, in this case $b=.1$, the animal starts to respond. The decrease in relative discrepancy is shown for $\lambda=1.0$ and $\mathrm{N}=5$, and for $\lambda=.67$ and $\mathrm{N}=6$. The inset shows the decision rule. (c) The long-term memory store from where $\mathrm{N}$ is retrieved contains the number of pulses reached in previous reinforced trials. (d) once the threshold is crossed, the response rate is high and constant. Two functions are shown, one with a start point at $5 \mathrm{~s}$ (when $\lambda=1.0$ and $\mathrm{N}=5$ ) and the other with a start point at $9 \mathrm{~s}$ (when $\lambda=.67$ and $\mathrm{N}=6$ ), each with a break and run pattern. (e) When the final response is reinforced, the number of pulses in the accumulator is transferred to the long-term memory store, 10 when $\lambda=1.0$ and 6 when $\lambda=.67$. These counts are now included in the long-term memory distribution shown in (c). (f) Averaged across many trials, the break and run pattern generated in individual trials yields a smooth sigmoid response rate function. 
the discrepancy falls below the threshold, $b$, the animal starts to respond at a relatively constant rate. As time elapses, the discrepancy reaches 0 and then increases because on peak trials the reinforcer is omitted and the trial is extended well past the usual reinforcement time. When the discrepancy exceeds the threshold, $b$, the animal ceases to respond. The net effect is a break-run-break pattern on a trial by trial basis and an average Gaussian-like function similar to the average data shown in Figures 23.4a and $23.4 \mathrm{~b}$.

Detailed analyses, however, suggest that to explain some experimental findings two independent thresholds, $b_{1}$ and $b_{2}$, may be necessary. Moreover, it seems that the two thresholds should be sampled from random variables with different means and variances (Church et al., 1994). In a twothreshold SET model, $b_{1}$ and $b_{2}$ determine the start and stop times, respectively, according to the modified decision rule

$$
-b_{2}<\frac{N-\lambda t}{N}<b_{1}
$$

For the bisection task, further elaborations are needed. Recall that in this task each trial involves one of two intervals, $S_{S}$ or $S_{L}$, say $2 \mathrm{~s}$ or $8 \mathrm{~s}$, respectively; once the interval elapses, the animal has, to classify the sample as short or long depending on its duration. Testing involves the presentation of unreinforced intermediate durations. To cllarify the description, let us assume that the correct responses after the $2 \mathrm{~s}$ and $8 \mathrm{~s}$ samples are red and green, respectively. Because the task involves two intervals, SET assumes that two fong-term memory stores are formed during training, containing the counts from previous experiences with the $2 \mathrm{~s}$ and $8 \mathrm{~s}$ samples. Figure 23. Th, shows the structure of SET for this task. As tsual, at stimulus onset a randomly drawn sample determines the pacemaker rate, $\lambda$, and the switch closes allowing the pulses to flow into the accumulator. Once the sample ends, the switch opens and the animal then compares the number of pulses in the accumulator $(\lambda t)$ with, not one but two samples, a sample retrieved from the $2 \mathrm{~s}$ long-term memory store $\left(\mathrm{N}_{\mathrm{R}}\right)$, and a sample retrieved from the $8 \mathrm{~s}$ long-term memory store $\left(\mathrm{N}_{\mathrm{G}}\right)$. If $\lambda t$ is more similar to $\mathrm{N}_{\mathrm{G}}$, the animal tends to classify the sample as long, otherwise it tends to classify the sample as short. Formally, the probability of choosing green is given by

$$
P(G)=P\left(\frac{\lambda t}{N_{R}}>\frac{N_{G}}{\lambda t}\right)
$$

Detailed analyses show that SET predicts the superimposition of psychometric functions when the ratio of the samples is held constant and the PSE at the geometric mean of the trained durations (see Gibbon, 1981). Figure 23.9 illustrates the dynamics of a $2 \mathrm{~s}$ sample and an $8 \mathrm{~s}$ sample trial according to SET.

As it can be surmised from the previous descriptions, SET is not a unitary modet but a family of models. Modifications can be implemented at each of its main components (the clock, the long-term memory, and the comparator) to accommodate the specificities of aparticular timing task, but caution is recommended. On the one hand, coherence requires that similar tasks should be tackled with similar if not equal models. On the other hand, noticeably different tasks may grant modifications to capture their distinctiveness (Wearden, 1999). Of course this distinction is not always clear and the proliferation of "family members" has prompted harsh critiques (e.g., Staddon \& Higa, 1999) and ultimately alternative models. We turn to one of such models next.

\section{The Learning-to-Time Model}

LeT (Machado, 1997; Machado et al., 2009) is a dynamic account of how time comes to control behavior, using as raw ingredients well-known principles of learning. Specifically, it relies on reinforcement, extinction, and generalization operationalized in fairly simple ways (e.g., linear learning rules) to predict and explain the temporal differentiation of behavior during acquisition and steady state. Because LeT does not appeal to specialized timing mechanisms but merely uses general and widely studied principles, we believe it sets the standard for those proposing complex and dedicated timing mechanisms.

Metaphorically, LeT spatializes time and the task of the animal is to learn through trial and success where relevant events (such as food) occur. The model has three components, whose basic structure 


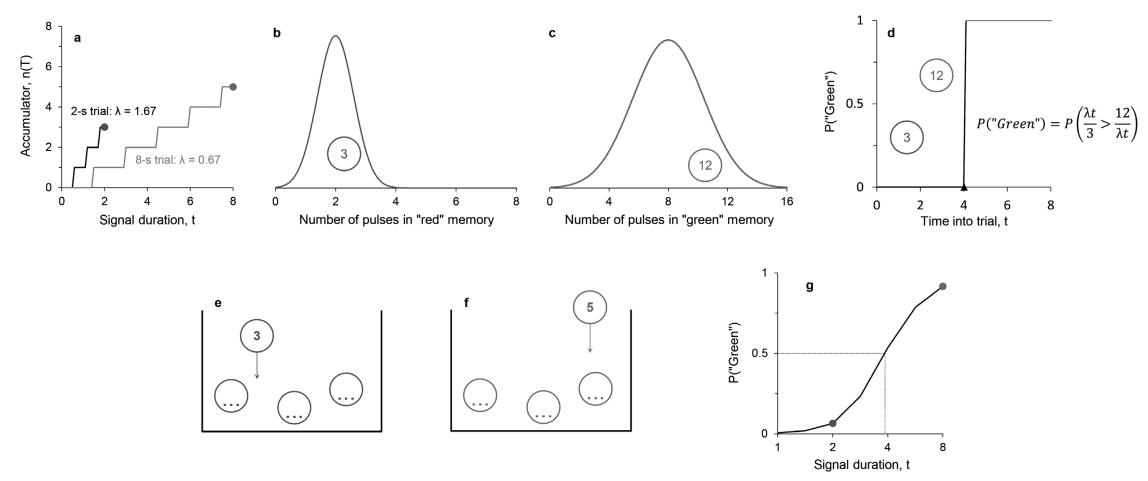

FIGURE 23.9. The dynamics of SET in a bisection task with a short sample of $2 \mathrm{~s}$ and a long sample of $8 \mathrm{~s}$ mapped onto red and green, respectively. (a) In all trials, the number of pulses in the accumulator increases at a rate $\lambda$ pulses. Two trials are show, a $2 \mathrm{~s}$ trial with $\lambda=1.67$ and an $8 \mathrm{~s}$ trial with $\lambda=.67$, with $\lambda$ sampled at the beginning of each trial from a normal distribution. When the signal terminates, the animal compares the number of pulses in the accunulator $(\lambda t)$ with two memory samples, one retrieved from (b) the 2 s long-term memory, $\mathrm{N}_{\mathrm{R}}=3$, and (c) the other from the $8 \mathrm{~s}$ long-term memory, $\mathrm{N}_{\mathrm{G}}=12$; the long-term memory stores from where $\mathrm{N}_{R}$ and $\mathrm{N}_{G}$ are retrieved contain the number of pulses reached in previous reinforced trials. (d) If the number of pulses in the accumulator is more similar to $\mathrm{N}_{\mathrm{G}}$, the animal tends to choose green, otherwise it is more likely to choose red. The inset shows the decision rule. If the animal chooses the correct response, the number of pulses in the accumulator is transferred to either (e) the $2 \mathrm{~s}$ long-term memory store or (f) the $8 \mathrm{~s}$ long-term memory store, depending on sample duration. These counts are now included in the long-term memory distributions shown in (b) and (c). (g) when the animal learns to correctly classify the two samples, new intermediate durations are introduced. Averaged across many trials, a smooth and ogival psychometric function is obtained, with a Point of Subjective Equality at the geometric mean of the trained durations.

is represented in Figure 23.10a: a set of behavioral states $(n=1,2, \ldots)$, a set of associative links connecting the states to the operant response, and the operant response itself. At the onset of a time marker, the states are activated seriatly, one at a time. With training they become differentially associated or coupled with the operant response. From these two features, temporal regulation emerges: As time passes, different states become active; active states strongly coupled with the operant response occasion that response, whereas active states weakly coupled with the operant response do not occasion it.

LeT describes performance in FI schedules as follows. Once a trial starts, the behavioral states activate serially, one at a time. The speed of activation, $\lambda$, is a Gaussian random variable, with mean $\mu$ and standard deviation $\sigma$ sampled at the beginning of each trial. The first state is active from 0 to $1 / \lambda$, the second from $1 / \lambda$ to $2 / \lambda$, and so on. In a FI $10 \mathrm{~s}$ schedule, for example, assume that $\lambda=1$ state/second at trial onset. Hence state $\mathrm{n}=10$ will be active at $10 \mathrm{~s}$ when the subject responds and receives food. On another trial, $\lambda$ might equal 0.8 states/second and state $n=8$ will be active at $10 \mathrm{~s}$. In other words, the state active at $10 \mathrm{~s}$ or shortly thereafter varies from trial to trial. The model's response rule states that although state $\mathrm{n} \geq 1$ is active, the animal responds if the strength of the link of that state, W(n), is greater than a threshold $\theta$. To mimic undifferentiated responding at the beginning of training, the initial strength (W0) of all links is greater than $\theta$.

Finally, when the subject responds and receives food, the link between the active state, $\mathrm{n}^{*}$, and the operant response increases by the amount $\Delta \mathrm{W}\left(\mathrm{n}^{*}\right)=\beta\left[1-\mathrm{W}\left(\mathrm{n}^{*}\right)\right]$, where $\beta>0$ is a reinforcement parameter, and the links from the earlier states $\left(\mathrm{n}<\mathrm{n}^{*}\right)$, active during extinction, 

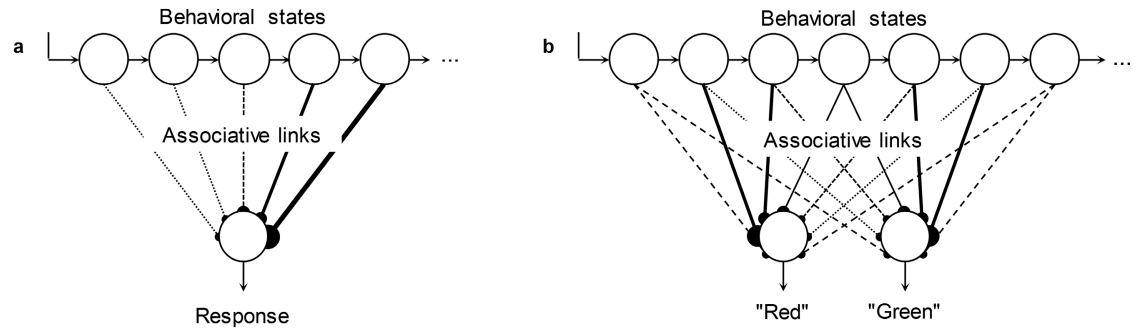

FIGURE 23.10. Components of the LeT model. A time marker initiates the activation of the behavioral states. Each state is associated with the operant response via the associative links. (a) In FI schedules, only one vector of associative links is formed coupling the behavioral states to the operant response. (b) In the bisection procedure, two vectors of associative links are formed connecting each state to each available response.

decrease by the amount $\Delta \mathrm{W}(\mathrm{n})=-\left(\alpha / \mathrm{n}^{*}\right) \mathrm{W}(\mathrm{n})$, where $\alpha>0$ is an extinction parameter. The links of all inactive states $\left(n>n^{*}\right)$ do not change their current strength. To summarize, the link strength of the reinforced state, $\mathrm{n}^{*}$, increases; that of all previous states, decreases; and that of all subsequent states does not change. Figure 23.11 illustrates the dynamics of a FI trial according to LeT.

The cumulative effect of reinforcement is to increase the links of the states more likely to be active at $10 \mathrm{~s}$; conversely, the cumulative effect of extinetion is to decrease the links of the states morelikely to be active before $10 \mathrm{~s}$. In particular, the links of the initial states decrease below $\theta$ and, hence, the subject ceases to respond at the beginning of the interval (the post-reinforcement pause). At the steady state, the link strengths express the cumulative effects of reinforcement and extinction - the animal's learning history-and form a distributed temporal memory.

The model predicts a break and run pattern for relatively short FIs and a scallop-like pattern for longer FIS'(Dews, 1978; Machado et al., 2009; Schneider, 1969); the average response rate function will be sigmoidal, similar to the data shown in Figures 23.2a and 23.2b. Interestingly, the model also predicts that if we extend the trial well beyond $\mathrm{T}$, responding should persist unabated for a long time, for the states that become active after T will have remained inactive during training and therefore will have preserved their initial links at $\mathrm{W} 0>\theta$.

The model accounts for the scalar property by means of its state activation dynamics and its extinction rule. Paraneter $\lambda$, the random variable that governs the speed of state transition, induces scalar variabilit in the active state at time $t$ (i.e., if $\mathrm{n}(\mathrm{t}) \approx \lambda \mathrm{t}$, $\arg (\mathrm{n}(\mathrm{t})) \approx \mu \mathrm{t}$, and $\left.\operatorname{var}(\mathrm{n}(\mathrm{t})) \approx \sigma^{2} \mathrm{t}^{2}\right)$. Moreoyer the decrease in the links of states active in extinetion is inversely proportional to the number of the reinforced state $\left(\alpha / n^{*}\right)$. The rule means that the effect of extinction decreases with $\mathrm{T}$ - the longer the FI value, $T$, the higher $\mathrm{n}^{*} \approx \mu \mathrm{T}$, and the smaller the effect of extinction, $\alpha /(\mu \mathrm{T})$, a result akin to the partial-reinforcement-extinction effect. As Machado et al. (2009) showed, this learning rule ensures that the scalar variability present in state activation transfers, as it were, to measurable response rate.

The extension of LeT to the peak procedure is straightforward. Because the states active past $\mathrm{T}$ have rarely been active during the FI training, the strength of their associative links is preserved above $\theta$. On peak trials, however, these states become active and lose their initial strength because of extinction. The net result is a Gaussian-like function similar to those displayed in Figures 23.4a and 23.4b.

To account for performance in the bisection task, we add to LeT's basic structure a second operant response and a new set of links between the behavioral states and that response. Thus, for the bisection task, each state has two sets of links, one to $R_{1}$ and the other to $R_{2}$. The learning and decision rules also change because the animal does not respond during the sample and, when it does, it must choose between two competing responses. Figure 

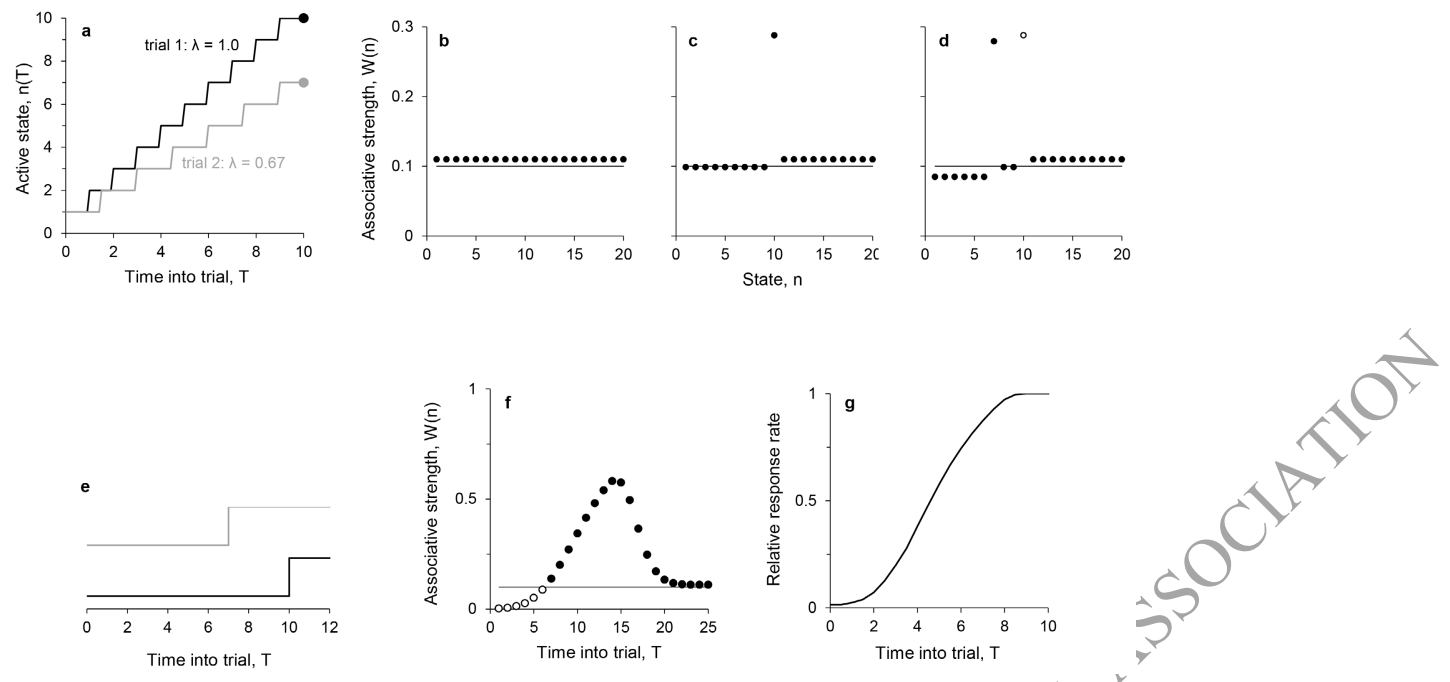

FIGURE 23.11. The dynamics of LeT in a FI 10-s schedule. (a) As time into the trial elapses, the behavioral states activate serially, one at a time, at a rate $\lambda$ pulses. Two trials are shown, one with $\lambda=.67$ and the other with $\lambda=1.0$, with $\lambda$ sampled at the beginning of each trial from a normal distribution. (b) at the outset or training, the initial strength, $\mathrm{W} 0$, of all associative links is greater than the response threshold, $\theta$. In this particular case, $W 0=.11$ and $\theta=.10$. (c) At the end of trial one, with $\lambda=1.0$, the links from states 1 to 9 weaken, the link from state 10 strengthens, and the links from the remaining states do not change. (d) at the end of trial 2, with $\lambda=.67$, the links from states 1 to 6 weaken, the link from state 7 strengthens, and the links from the other states do not change; the white circle represents the link strengthened in trial one. (e) because the link strength of states beyond the active sate at $10 \mathrm{~s}$ is above threshold, the response profile is break-and-run: When $\lambda=1.0$, responding starts at $10 \mathrm{~s}$ and when $\lambda=.67$ responding starts at $7 \mathrm{~s}$. (f) at steady state, the link profile shows that state 7 is the first state with a link strength above the threshold. The animal will start to respond when state 7 becomes active. (g) given the variability in the speed of the transition parameter, the average relative response rate curve is sigmoidal, reaching 0.5 at $6 \mathrm{~s}$ into the trial.

23.10b shows the structure of LeT for this task. To illustrate how the model works, consider a bisection task with $\mathrm{S}_{\mathrm{s}}=2 \mathrm{~s}$ and $\mathrm{S}_{\succ}=8 \mathrm{~s}$, and red and green keys as choice alternatives. The animal is rewarded for choosing red after the $2 \mathrm{~s}$ samples, and green after the $8 \mathrm{~s}$ samples. Assume that on a $2 \mathrm{~s}$ trial, state $\mathrm{n}=$ 2 is active at the end of the sample. The new decision rule states that the subject chooses red according to the relative strength of the links from state 2 to red and green. If we represent the links from state 2 to red and green as WR(2) and WG(2), respectively, then the probability of choosing red equals WR(2) / [WR(2) + WG(2)]. If the subject does choose red and receives food, the link between state 2 and red increases by the amount $+\beta[1-\mathrm{WR}(2)]$ and the link between state 2 and green decreases by the amount $-\beta W G(2)$; if instead the subject responds green (and does not receive a reward), the link between state 2 and green decreases by - $\alpha \mathrm{WG}(2)$ and the link between state 2 and red increases by the amount $+\alpha[1-\mathrm{WR}(2)]$. The same learning rule applies on the $8 \mathrm{~s}$ trials. According to LeT, training promotes choosing red and avoiding green after $2 \mathrm{~s}$ samples, and choosing green and avoiding red after 8 s samples.

Because the first states in the series are more likely to be active at the end of $\mathrm{S}_{\mathrm{S}}$, whereas subsequent states are more likely to be active at the end of $\mathrm{S}_{\mathrm{L}}$, reinforcement and extinction bias the first states toward red and the subsequent states toward green. During test trials, as the sample duration increases and successive states become active, the probability 
of choosing green over red increases. The net effect is the sigmoid psychometric function typically observed in the bisection task, as those shown in Figure 23.6a, with the point of subjective equality near the geometric mean of the trained stimuli.

Figure 23.12 illustrates the dynamics of a 2 s sample and an 8 s sample trial according to LeT.

Interestingly, LeT predicts that the subjects should be indifferent between red and green following intervals considerably shorter than $2 \mathrm{~s}$ and considerably longer than $8 \mathrm{~s}$. Because states active at durations considerably shorter than 2 s or considerably longer than $8 \mathrm{~s}$ are rarely active during training, their initial link strength (W0) to red and green is preserved. If the generalization tests include not only durations in the $2 \mathrm{~s}$ to $8 \mathrm{~s}$ range, but also durations outside this range, the predicted generalization gradient should be politonic: preference for green should decrease from indifference to 0 as $t$ ranges from $0 \mathrm{~s}$ to $2 \mathrm{~s}$, increase from 0 to 1 as $t$ ranges from $2 \mathrm{~s}$ to $8 \mathrm{~s}$, and finally decrease to indifference for $\mathrm{t}>8 \mathrm{~s}$. Some studies found politonic gradients consistent with LeT (e.g., de Carvalho, Machado, \& Tonneau, 2016; Russell \& Kirkpatrick, 2007; Siegel, 1986; Vieira de Castro, Machado, \& Tomanari, 2013), but some of these same studies and other studies have also found gradients inconsistent with LeT, at least for the longest testdurations (de Carvalho, Machado, \& Tonneau, 2016; Siegel, 1986; Vieira de Castro \& Machado, 2012).
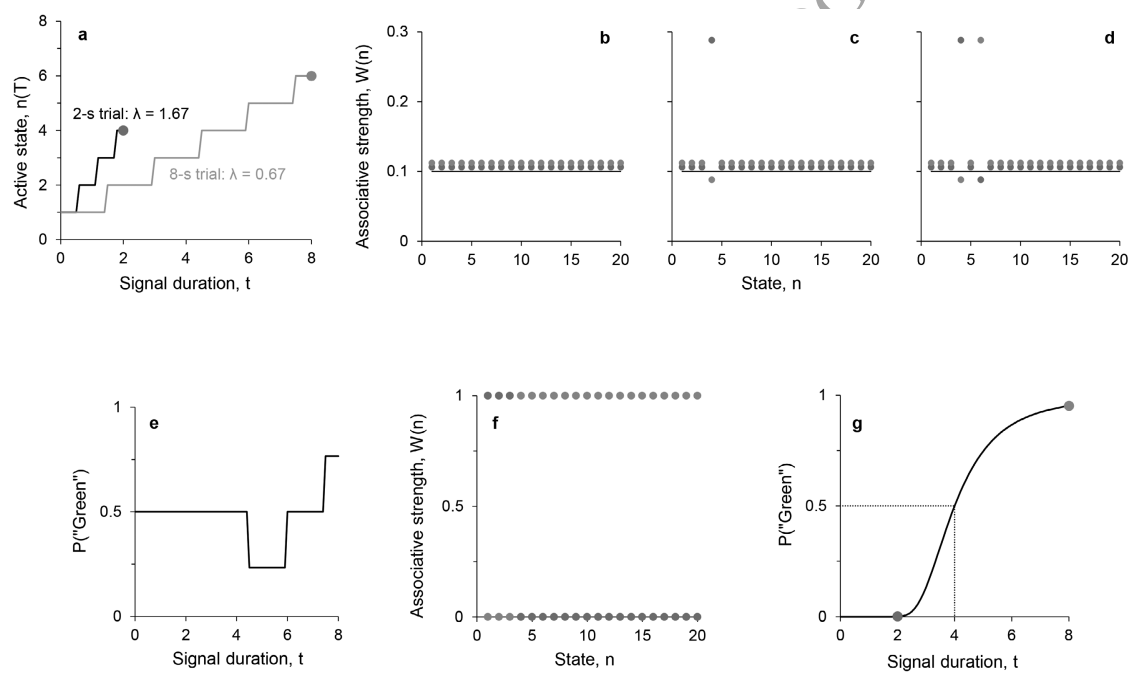

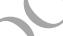

FIGURE 23.12. The dynamics of SET in a bisection task with a short sample of $2 \mathrm{~s}$ and a long sample of $8 \mathrm{~s}$ mapped onto red and green, respectively. (a) As time elapses, the behavioral states activate serially, one at a time, at a rate $\lambda$ pulses. Two trials are show, the first a $2 \mathrm{~s}$ trial with $\lambda=1.67$ and the second an $8 \mathrm{~s}$ trial with $\lambda=.67$, with $\lambda$ sampled at the beginning of each trial from a normal distribution. (b) initially, all associative strengths, W0, connecting each state to the two possible responses are greater than the threshold, $\theta$, with $\mathrm{W} 0=.11$ and $\theta=.10$ (we offset the links with green slightly to the right to prevent their overlap with the links with red). (c) At the end of trial one, state 4 was active and its link governs choice. Because the animal responded correctly and was rewarded, the link from state 4 to red strengthens and the link from state 4 to green weakens. (d) the learning process repeats at the end of trial two, this time with state 6: its link with green strengthens and its link with red weakens. (e) considering the strength profiles at the end of trial two, the probability of choosing green varies as a function of the sample duration (note that here the $x$-axis is time, not states). (f) at the steady state, the profile of link strengths is well differentiated, inducing ( $g$ ) the usual smooth and ogival psychometric function, with a Point of Subjective Equality at the geometric mean of the trained durations. 
To summarize, LeT takes three full-fledged principles of learning-stimulus generalization, reinforcement, and extinction—as its foundation stone and is able to account for some of the most relevant findings in the interval timing domain. Through a series of sates, associative links, and operant responses the animal learns an important regularity in its environment, the correlation between time and a biologically potent event such as food.

\section{Contrasting Models of Interval Timing} The comparison of models is an utterly important scientific endeavor. Before long, as models proliferate, its relevance will only upsurge. Several models are able to accommodate the most robust findings in the field of interval timing (e.g., the scalar property, FI, peak performance). We are left with the arduous task of disentangling the models, in terms of their structure and dynamics and their successes and frailties. Statistics may help, but decisions on the basis of small differences in, for example, variance accounted for, seem unsuitable. Still, some of these aspirations can be accomplished by conceptual analyses; others require critical experiments. Here, we aim at contrasting SET and LeT.

Albeit SET and LeT are clearly disparate models in terms of background, dynamics, and even language, they do bear some similarities. They both include a mechanism to keep track of time: the clock (i.e., the pacemaker and accumulator) in SET and the serial organization of states in LeT. On each trial, the pacemaker emits pulses at rate $\lambda$ (SET) or the states are activated at rate $\lambda$ (LeT). At each particular moment in the trial, the number of pulses in the accumulator (SEN) or the active state (LeT) represents elapsed time. The learning history is also present in both models; as a distribution of (subjective) reinforced times in SET and as differently weighed vectors of associative links in LeT.

Despite these similarities, the models differ in numerous ways mainly because they differ in regard to the learning mechanisms and to what is actually learned in timing tasks. Two of the differences should be conspicuous straightaway: First, whereas SET posits dedicated structures or modules to deal with temporal tasks, LeT relies on general principles of learning (reinforcement, extinction, and generalization) to engender temporally regulated behavior; second, SET captures the steady-state temporal regulation of behavior paying little attention to how it emerges, whereas LeT is a learning model with a strong emphasis on the acquisition of temporal control. Following Machado et al. (2009), we focus our discussion in the structure of memory, the effect of time in retrieval, the contents of memory, and the effect of context on temporally regulated behavior.

The structure of memory differs greatly between the models (cf. Figures 23.7 and 23.10).In SET, long-term memory is concentrated in stores with no particular internal organization. It can literally be conceived as an urn containing balls with the number of pulses inscribed, each ball with the same probability of being selected at retrieval. LeT, on the other hand, conceives of memory as distributed in the links connecting the states to the response. Although, LeT does not strictly speak of memory sampling, the strength of each link is effectively "sampled" only when its coupled state is active. Hence, in LeT, one can conceive of memory as serially structured by state activations.

The just mentioned differences in the structure of memory introduce differences in retrieval, too. In SET, retrieval is time-independent. At any given moment (i.e., regardless of the current number in the accumulator) a sample from long-term memory can be retrieved. The same is not true of LeT: memories, in this case the strength to the associative links, can be accessed only when the coupled sate is active. This makes retrieval time-dependent because the active state represents elapsed time.

Another difference motivated by the models' dynamics concerns the contents of memory. Consider for instance a FI T-s reinforcement schedule. According to SET, when the animal emits the first response after $\mathrm{T}$ and is reinforced the number of pulses representing elapsed time is transferred from the accumulator to the long-term memory store. If, however, no reinforcer is given, nothing is added to memory. The same is true for all responses occurring before $\mathrm{T}$. In other words, memory represents only local relative rates of reinforcement because extinction is left out of the model. Conversely, because LeT considers reinforcement 
and extinction, the associative links represent the moments of reinforcement and the local absolute rates of reinforcement. The former by the link that is strengthened and the latter by how strong each link is relative to the others. Borrowing an analogy from Machado et al. (2009), the distinction is similar to the one between relative and absolute frequency histograms. In LeT, the strength of the associative links are like an absolute frequency histogram because one can determine (a) whether reinforcement is more likely to occur at one moment than another, say $t_{1}$ and $t_{2}$, but also (b) how frequent reinforcement is at $t_{1}$ and $t_{2}$. On the other hand, memory in SET resembles a relative frequency histogram because the animal can infer (a) but not (b) from its contents.

Finally, to fully appreciate the effect of context in memory, we will rely on a task for which SET and LeT make contrasting predictions-the double bisection (Machado \& Keen, 1999). The task combines two simple bisections sharing one sample duration. Suppose that in one bisection, the animal learns to choose red after a $1 \mathrm{~s}$ sample and to choose green after a $4 \mathrm{~s}$ sample. Suppose further that in the other bisection the animal is reinforced for choosing blue after a $4 \mathrm{~s}$ sample and for choosing yellow after a 16 s sample. Crucially, the correct choice for the common $4 \mathrm{~s}$ sample differs in the two bisections: green in the first and blue in the second. Once the animal masters both simple bisections, probe trials with samples ranging from 1 to $1,6 \mathrm{~s}$ and with green and blue comparisons are introduced. Both colors were associated with the 4-s sample, but their contexts differed. Green was embedded with the 1-s sample and red response, whereas the context for blue was the 16-s sample associated with yellow.

Assuming that animals do not have an a priori bias fora color, SET predicts indifference between green and blue regardless of sample duration. The rationale is as follows: During training the animal forms four long-term memories, one per sample duration, indexed by the corresponding correct color (say, $\mathrm{M}_{\text {red }}, \mathrm{M}_{\text {green }}, \mathrm{M}_{\text {blue }}$, and $\mathrm{M}_{\text {yellow }}$ ). Because the content of each memory store depends only on the reinforced interval, the contents of $\mathrm{M}_{\text {green }}$ and $\mathrm{M}_{\text {blue }}$ will be identical (i.e., the distribution of pulses will have the same mean and standard deviation).
Therefore, on a probe trial, when the $t$-s sample elapses, with $1 \geq t \geq 16$, the animal will compare the number of pulses in the accumulator with two samples retrieved from memories with identical distributions. The net result is indifference between green and blue independently of the sample duration. This prediction stems directly from the fact that, according to SET, the contents of a particutar memory store depend only on the reinforced duration indexed by a particular response with no interference from the context. In other words, in SET, memory is context independent.

For LeT, however, the contexts in which green and blue are reinforced and extinguished are paramount. Put differently, memory is context dependent. At the outset of training, all states are linked equally to blue and green. As the animals learn the two bisections, the choice of green is extinguished when the early states are active because those are most probably 1 s sample trials and the choice of blue is extinguished when the late states are active because those are most probably 16 s sample trials. Because of these trade-offs, by the end of training blue is more strongly linked to early states than green, and vice-versa for late states. This pattern of correlations predicts that preference for green over blue should increase with sample duration-a context effect.

Several studies have yielded data consistent with LeT but not SET: Preference for green increases monotonically with sample duration (e.g., Arantes \& Machado, 2008; Machado \& Keen, 1999; Machado \& Oliveira, 2009; Machado \& Pata, 2005; Oliveira \& Machado, 2008, 2009). Figure 23.13 contrasts the models' predictions with the context effect reported by Machado and Keen (1999).

On the whole, SET and LeT have some affinities but the differences are unassailable particularly concerning the properties of memory and what is actually learned in timing tasks. On the empirical side, both can account for the most fundamental findings in the interval timing realm; SET's failure in the double bisection task is diagnostic but probably not fatal. We prefer to emphasize more critical issues on the theoretical front. Despite SET's intuitive appeal and influence in the animal and human literature, LeT has its foundations on the solid ground 


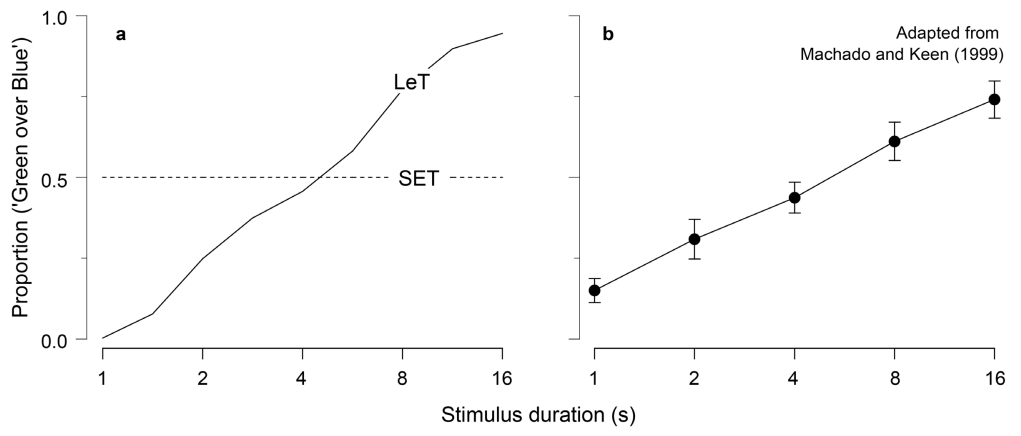

FIGURE 23.13. Proportion of choices of green over blue as a function of stimulus duration in a double bisection task. (a) SET and LeT predictions. (b) Average preference for green ( $\mathrm{n}=8$ pigeons). Note the logarithmic scale on the $x$-axis. From "Learning-to-Time (LeT) or Scalar Expectancy Theory (SET)? A Critical Test of Two Models of Timing," by A. Machado, and R. Keen, 1999, Psychological Science, 10, p. 289. Copyright 1999 by Sage. Adapted with permission.

of well-established and general learning principles confirmed across species and research domains. As stated elsewhere (de Carvalho, Machado, \& Vasconcelos, 2016), we advocate that LeT should be taken as a prudent null hypothesis. In our view, the proposal of more sophisticated timing abilities requires a clear treatment of acquisition processes, an equal degree of mathematical explicitness, and a convincingly better account of experimental data.

\section{CONCLUSION}

The ability of animals to regulate their behavior spans several orders of magnitude, from seconds to years. Circannual rhythms allow animals to anticipate upcoming seasonal changes increasing their probability of survival and reproduction. Circadian rhythms bestow animats the ability to adjust to the daily light-dark aycle allowing them to prepare for recurring events such as when and where food is available and when and where the risk of predation is high. Interval timing, on the other hand, deals with the animals' ability to temporally regulate their behavior in the range well below 24 hours as a function of biologically relevant events.

Temporal regularities in the range of seconds to minutes may, at first glance, appear artificial but as we have seen they pervade many superficially severed spheres of animal behavior, from foraging to communication. The bulk of research in interval timing has fitly resorted to the controlled conditions of the laboratory to expose its pivotal properties and mechanisms. Within certain boundary conditions, the psychophysics of animal timing is currently well characterized; many experimental procedures have been devised to study distinct facets of this ability such as concurrent and retrospective time perception. In virtually all of them, the hallmark of interval timing surfaced-the scalar property.

The advancements on the empirical side went hand in hand with theoretical developments through the development of a variety of explanatory models. Here, we introduced and compared two of such models: SET and LeT. Both models account well for most data but differ in their assumptions, structure and dynamics. Because LeT is based on basic principles of learning, we contend that it should be taken as an informed first hypothesis before advancing more elaborate processes.

Meanwhile, many questions remain unanswered. For instance, what is the shape of the psychometric function outside the trained range in a bisection task? Also, do inhibitory processes play a role in temporal control? Recall, for example that in a FI, as training proceeds, animals stop responding in the first section of the interval. Is this simply caused by the lack of excitation or by inhibition as well? The answers to these and many other questions may help to untangle models but, most important, they will 
spawn new questions and perhaps new procedures, keeping the momentum of the captivating field of interval timing.

\section{References}

Arantes, J., \& Machado, A. (2008). Context effects in a temporal discrimination task: Further tests of the scalar expectancy theory and learning-totime models. Journal of the Experimental Analysis of Behavior, 90, 33-51. http://dx.doi.org/10.1901/ jeab.2008-90-33

Balci, F., Gallistel, C. R., Allen, B. D., Frank, K. M., Gibson, J. M., \& Brunner, D. (2009). Acquisition of peak responding: What is learned? Behavioural Processes, 80, 67-75. http://dx.doi.org/10.1016/j. beproc.2008.09.010

Baptista, L. F., \& Morton, M. L. (1988). Song learning in montane white-crowned sparrows: From whom and when. Animal Behaviour, 36, 1753-1764. http:// dx.doi.org/10.1016/S0003-3472(88)80114-3

Barreto, R. E., Rodrigues, P., Luchiari, A. C., \& Delicio, H. C. (2006). Time-place learning in individually reared angelfish, but not in pearl cichlid. Behavioural Processes, 73, 367-372. http://dx.doi.org/10.1016/j. beproc. 2006.06.001

Beecher, M. D., \& Brenowitz, E. A. (2005). Functional aspects of song learning in songbirds. Trends in Ecology and Evolution, 20, 143-149. http://dx.doi.org/10.1016/j. tree.2005.01.004

Beecher, M. D., Campbell, S. E., \& Stoddard, P. K. (1994). Correlation of song learning and territory establishment strategies in the song sparrow. Proceedings of the National Academy of Sciences, USA, 91, 1450-1454. http://dx.doi.org/10.1073/pnas.914 1450

Beling, I. (1929). Über das Zeitgedächthnis der Bienen [About the time memory of bees] Zeitschrift für Vergleichende Physiologie, 9, 259-338 http://dx.doi.org/10.1007/ BF00340159

Biebach, H., Falk, H. \&Krebs, J. R. (1991). The effect of constant light and phase shifts on a learned time-place association in garden warblers (Sylvia borin): Hourglass or circadian clock? Journal of Biological Rhythms, 6, 353-365. http://dx.doi. org $10.1177 / 074873049100600406$

Biebach, H., Gordijn, M., \& Krebs, J. R. (1989). Timeand-place learning by garden warblers, Sylvia borin. Animal Behaviour, 37, 353-360. http://dx.doi. org/10.1016/0003-3472(89)90083-3

Boisvert, M. J., \& Sherry, D. F. (2006). Interval timing by an invertebrate, the bumble bee Bombus impatiens. Current Biology, 16, 1636-1640. http://dx.doi.org/10.1016/j. cub.2006.06.064

Bolles, R. C., \& Moot, S. A. (1973). The rat's anticipation of two meals a day. Journal of Comparative and
Physiological Psychology, 83, 510-514. http://dx.doi. org/10.1037/h0034666

Brunner, D., Kacelnik, A., \& Gibbon, J. (1992). Optimal foraging and timing processes in the starling, Sturnus vulgaris: Effect of inter-capture interval. Animal Behaviour, 44, 597-613. http://dx.doi.org/10.1016/ S0003-3472(05)80289-1

Cabeza de Vaca, S., Brown, B. L., \& Hemmes, N. S. (1994). Internal clock and memory processes in animal timing. Journal of Experimental Psychology: Animal Behavior Processes, 20, 184-198. http:/y dx.doi.org/10.1037/0097-7403.20.2.184

Cain, S. W., Chou, T., \& Ralph, M. R. (2004). Circadian modulation of performance on an aversion-based place learning task in hamsters. Behavioural Brain Research, 150, 201-205. http://dx.doi.org/10.1016/j. bbr.2003.07.001

Carr, J. A. R., Tan, A. O.. \&Wilkie, D. M. (1999). Further evidence that rats use ordinal timing in a daily time-place learning task. Behavioural Processes, 48, 35-48. http://dx.doi.org/10.1016/ S0376-6357(e99)00074-1

Carr, J. A. R., \& Wilkie, D. M. (1997). Rats use an ordinal timer in a daily time-place learning task. Journal of Experimental Psychology: Animal Behavior Processes, 23, 232-247. http://dx.doi.org/10.1037/00977403.23.2.232

Catania, A. C. (1970). Reinforcement schedules and psychophysical judgment: A study of some temporal properties of behavior. In W. N. Schoenfeld (Ed.), The theory of reinforcement schedules (pp. 1-42). New York, NY: Appleton-Century-Crofts.

Catania, A. C., \& Reynolds, G. S. (1968). A quantitative analysis of the responding maintained by interval schedules of reinforcement. Journal of the Experimental Analysis of Behavior, 11, 327-383. http://dx.doi.org/10.1901/jeab.1968.11-s327

Charnov, E. L. (1976). Optimal foraging, the marginal value theorem. Theoretical Population Biology, 9, 129-136. http://dx.doi.org/10.1016/00405809(76)90040-X

Cheng, K., \& Westwood, R. (1993). Analysis of single trials in pigeons' timing performance. Journal of Experimental Psychology: Animal Behavior Processes, 19, 56-67. http://dx.doi.org/10.1037/00977403.19.1.56

Cheng, K., Westwood, R., \& Crystal, J. D. (1993). Memory variance in the peak procedure of timing in pigeons. Journal of Experimental Psychology: Animal Behavior Processes, 19, 68-76. http://dx.doi.org/10.1037/00977403.19.1.68

Church, R. M., \& Broadbent, H. A. (1990). Alternative representations of time, number, and rate. Cognition, 37, 55-81. http://dx.doi.org/10.1016/00100277(90)90018-F 
Church, R. M., \& Deluty, M. Z. (1977). Bisection of temporal intervals. Journal of Experimental Psychology: Animal Behavior Processes, 3, 216-228. http://dx.doi.org/10.1037/0097-7403.3.3.216

Church, R. M., \& Gibbon, J. (1982). Temporal generalization. Journal of Experimental Psychology: Animal Behavior Processes, 8, 165-186. http://dx.doi. org/10.1037/0097-7403.8.2.165

Church, R. M., Meck, W. H., \& Gibbon, J. (1994). Application of scalar timing theory to individual trials. Journal of Experimental Psychology: Animal Behavior Processes, 20, 135-155. http://dx.doi.org/10.1037/00977403.20.2.135

Cody, M. L. (1971). Finch flocks in the Mohave desert. Theoretical Population Biology, 2, 142-158. http:// dx.doi.org/10.1016/0040-5809(71)90012-8

Cox, R. T., \& Carlton, C. E. (1988). Paleoclimatic influences in the evolution of periodical cicadas (Insecta: Homoptera: Cicadidae: Magicicada spp.). American Midland Naturalist, 120, 183-193. http:// dx.doi.org/10.2307/2425898

Cox, R. T., \& Carlton, C. E. (1991). Evidence of genetic dominance of the 13-year life cycle in periodical cicadas (Homoptera: Cicadidae: Magicicada spp.). American Midland Naturalist, 125, 63-74. http:// dx.doi.org/10.2307/2426370

Crystal, J. D. (2006). Sensitivity to time: Implications for the representation of time. In E. A. Wasserman \& T. R. Zentall (Eds.), Comparative cognition: Experimenta explorations of animal intelligence (pp. 270-284). New York, NY: Oxford University Press.

Crystal, J. D., \& Baramidze, G. T. (2007). Endogenous oscillations in short-interval timing. Behavioural Processes, 74, 152-158. http://dx.doi.org/10.1016/j. beproc.2006.10.008

Daan, S., \& Koene, P. (1981). On the timing of foraging flights by oystercatchers, Haematopus ostralegus, on tidal mudflats. Netherlands Journal of Sea Research, 15, 1-22. http://dx.doi.org/10.1016/00777579(81)90002-8

Davidson, A. J., \& Menaker, M. (2003). Birds of a feather clock together-sometimes: Social synchronization of circadian rhythms. Current Opinion in Neurobiology, 13, 765-769. http://dx.doi.org/10.1016/j. conb.2003.10.011

Davies, N. B., \& Houston, A. I. (1981). Owners and satellites: The economics of territory defense in the pied wagtail, Motacilla alba. Journal of Animal Ecology, 50, 157-180. http://dx.doi.org/10.2307/4038

de Carvalho, M. P., Machado, A., \& Tonneau, F. (2016). Learning in the temporal bisection task: Relative or absolute? Journal of Experimental Psychology: Animal Learning and Cognition, 42, 67-81. http://dx.doi. org/10.1037/xan0000089 de Carvalho, M. P., Machado, A., \& Vasconcelos, M. (2016). Animal timing: A synthetic approach. Animal Cognition, 19, 707-732. http://dx.doi.org/10.1007/ s10071-016-0977-2

Delicio, H. C., \& Barreto, R. E. (2008). Time-place learning in food-restricted Nile tilapia. Behavioural Processes, 77, 126-130. http://dx.doi.org/10.1016/j. beproc.2007.06.005

Dews, P. B. (1970). The theory of fixed-interval responding. In W. N. Schoenfeld (Ed.), The theory of reinforcement schedules (pp. 43-61). New York, NY. Appleton-Century-Crofts.

Dews, P. B. (1978). Studies on responding under fixedinterval schedules of reinforcement: $\mathrm{H}$. The scalloped pattern of the cumulative record. Journal of the Experimental Analysis of Behavior, 29, 67-75. http:// dx.doi.org/10.1901/jeab.1978.29-67

Dragoi, V., Staddon, J. E. R. Palmer, R. G., \& Buhusi, C. V. (2003). Interval timing as an emergent learning property. Psychological Review, 110, 126-144.

Ferster, C. B., \& Skinner, B. F. (1957). Schedules of reinforcement. http://dx.doi.org/10.1037/10627-000

Frisch, B., \& Aschoff, J. (1987). Circadian rhythms in honeybees: Entrainment by feeding cycles. Physiological Entomology, 12, 41-49. ht tp;//dx.doi.org/10.1111/j.1365-3032.1987.tb00722.x

Gallistel, C. R. (1990). The organization of learning. Cambridge, MA: MIT Press.

Gibbon, J. (1977). Scalar expectancy theory and Weber's law in animal timing. Psychological Review, 84, 279-325. http://dx.doi.org/10.1037/0033295X.84.3.279

Gibbon, J. (1981). On the form and location of the psychometric bisection function for time. Journal of Mathematical Psychology, 24, 58-87. http://dx.doi. org/10.1016/0022-2496(81)90035-3

Gibbon, J. (1991). Origins of scalar timing. Learning and Motivation, 22, 3-38. http://dx.doi.org/10.1016/00239690(91)90015-Z

Gibbon, J. (1992). Ubiquity of scalar timing with a Poisson clock. Journal of Mathematical Psychology, 36, 283-293. http://dx.doi.org/10.1016/00222496(92)90041-5

Gibbon, J., \& Church, R. M. (1984). Sources of variance in an information processing theory of timing. In H. L. Roitblat, T. G. Bever, \& H. S. Terrace (Eds.), Animal cognition (pp. 465-487). Hillsdale, NJ: Erlbaum.

Gibbon, J., \& Church, R. M. (1990). Representation of time Cognition, 37, 23-54. http://dx.doi.org/10.1016/00100277(90)90017-E

Gibbon, J., \& Church, R. M. (1992). Comparison of variance and covariance patterns in parallel and serial 
theories of timing. Journal of the Experimental Analysis of Behavior, 57, 393-406. http://dx.doi.org/10.1901/ jeab.1992.57-393

Gibbon, J., Church, R. M., \& Meck, W. H. (1984). Scalar timing in memory. Annals of the New York Academy of Sciences, 423, 52-77. ht tp://dx.doi.org/10.1111/j.1749-6632.1984.tb23417.x

Gibson, J. S., \& Uetz, G. W. (2008). Seismic communication and mate choice in wolf spiders: Components of male seismic signals and mating success. Animal Behaviour, 75, 1253-1262. http:// dx.doi.org/10.1016/j.anbehav.2007.09.026

Grant, P. R. (2005). The priming of periodical cicada life cycles. Trends in Ecology and Evolution, 20, 169-174. http://dx.doi.org/10.1016/j.tree.2005.01.016

Grossberg, S., \& Schmajuk, N. A. (1989). Neural dynamics of adaptive timing and temporal discrimination during associative learning. Neural Networks, 2, 79-102. http://dx.doi.org/10.1016/08936080(89)90026-9

Guilhardi, P., \& Church, R. M. (2004). Measures of temporal discrimination in fixed-interval performance: A case study in archiving data. Behavior Research Methods, Instruments, and Computers, 36, 661-669. http://dx.doi.org/10.3758/BF03206548

Guilhardi, P., Yi, L., \& Church, R. M. (2007). A modular theory of learning and performance. Psychonomic Bulletin and Review, 14, 543-559. http://dx.doi.org/10.3758/BF03196805

Gwinner, E. (2001). Bird migration: It's control by endogenous clocks. In D. Baltimore, J. M. Allman, J. J. Hopfield, \& E. B. Lewis (Eds.), Frontiers of life: Vol 4. The living world (pp. 193-206). San Diego, CA: Academic Press.

Gwinner, E. (2012). Circannual rhythms: Endogenous annual clocks in the organization of seasonal processes. Berlin, Germany: Springer-Verlag.

Henderson, J., Hurly, T. A., Bateson, M., \& Healy, S. D. (2006). Timing in free-living rufous hummingbirds, Selasphorus rufus. Current Biology, 16, 512-515. http://dx.doi.org/10.1016/j. cub.2006.01.054

Hoppensteadt, F. C. \& Keller, J. B. (1976). Synchronization of periodical cicada emergences. Science, 194, 335-337. http://dx.doi.org/10.1126/ science 987617

Jozefowiez, J Staddon, J. E. R., \& Cerutti, D. T. (2009). The behavioral economics of choice and interval fiming. Psychological Review, 116, 519-539. http:// dx.doi.org/10.1037/a0016171

Kacelnik, A. (1984). Central place foraging in starlings (Sturnus vulgaris). I. Patch residence time. Journal of Animal Ecology, 53, 283-299. http://dx.doi. org/10.2307/4357

Kacelnik, A., \& Brunner, D. (2002). Timing and foraging: Gibbon's scalar expectancy theory and optimal patch exploitation. Learning and Motivation, 33, 177-195. http://dx.doi.org/10.1006/lmot.2001.1110
Kaiser, D. H. (2008). The proportion of fixed interval trials to probe trials affects acquisition of the peak procedure fixed interval timing task. Behavioural Processes, 77, 100-108. http://dx.doi.org/10.1016/j. beproc.2007.06.009

Kaiser, D. H., Zentall, T. R., \& Neiman, E. (2002). Timing in pigeons: Effects of the similarity between intertrial interval and gap in a timing signal. Journal of Experimental Psychology: Animal Behavior Processes, 28, 416-422. http://dx.doi.org/10.1037/00977403.28.4.416

Karsch, F. J., Robinson, J. E., Woodfill, C. J., \&Brown, M. B. (1989). Circannual cycles of luteinizing hormone and prolactin secretion in ewes during prolonged exposure to a fixed photoperiod: Evidence for an endogenous reproductive rhythm. Biology of Reproduction, 41, 1034-1046.http://dx.doi.org/10.1095/ biolreprod41.6.1034

Killeen, P. R., \& Fetterman, J. G. (1988). A behavioral theory of timing. Psychological Review, 95, 274-295. http://dx.doi.erg/10.1037/0033-295X.95.2.274

Kirkpatrick, K. (2002). Packet theory of conditioning and timing. Behavioural Processes, 57, 89-106. http:// dx.dói.org/10.1016/S0376-6357(02)00007-4

Kirkpátrick-Steger, K., Miller, S. S., Betti, C. A., \& CWasserman, E. A. (1996). Cyclic responding by pigeons on the peak timing procedure. Journal of Experimental Psychology: Animal Behavior Processes, 22, 447-460. http://dx.doi.org/10.1037/00977403.22.4.447

Kondo, N., Sekijima, T., Kondo, J., Takamatsu, N., Tohya, K., \& Ohtsu, T. (2006). Circannual control of hibernation by HP complex in the brain. Cell, 125, 161-172. http://dx.doi.org/10.1016/j. cell.2006.03.017

Krishnan, B., Dryer, S. E., \& Hardin, P. E. (1999). Circadian rhythms in olfactory responses of Drosophila melanogaster. Nature, 400, 375-378. http://dx.doi.org/10.1038/22566

Kyriacou, C. P., \& Hastings, M. H. (2010). Circadian clocks: Genes, sleep, and cognition. Trends in Cognitive Sciences, 14, 259-267. http://dx.doi.org/10.1016/j. tics.2010.03.007

Leak, T. M., \& Gibbon, J. (1995). Simultaneous timing of multiple intervals: Implications of the scalar property. Journal of Experimental Psychology: Animal Behavior Processes, 21, 3-19. http://dx.doi.org/10.1037/00977403.21.1.3

Lejeune, H., \& Wearden, J. H. (1991). The comparative psychology of fixed-interval responding: Some quantitative analyses. Learning and Motivation, 22, 84-111. http://dx.doi.org/10.1016/00239690(91)90018-4

Lejeune, H., \& Wearden, J. H. (2006). Scalar properties in animal timing: Conformity and violations. Quarterly 
Journal of Experimental Psychology, 59, 1875-1908. http://dx.doi.org/10.1080/17470210600784649

Lewis, S. M., \& Cratsley, C. K. (2008). Flash signal evolution, mate choice, and predation in fireflies. Annual Review of Entomology, 53, 293-321. http://dx.doi.org/10.1146/annurev. ento.53.103106.093346

Lima, J. (2010). Invariância da escala temporal com programas de intervalos fixos misturados [Temporal scale invariance with mixed fixed intervals programs]. Unpublished master's thesis, University of Minho, Braga, Portugal.

Lincoln, G. A., Clarke, I. J., Hut, R. A., \& Hazlerigg, D. G. (2006). Characterizing a mammalian circannual pacemaker. Science, 314, 1941-1944. http://dx.doi.org/10.1126/science.1132009

Lloyd, M., \& Dybas, H. S. (1966a). The periodical cicada problem. I. Population ecology. Evolution; International Journal of Organic Evolution, 20, 133-149. http://dx.doi.org/10.2307/2406568

Lloyd, M., \& Dybas, H. S. (1966b). The periodical cicada problem. II. Evolution. Evolution; International Journal of Organic Evolution, 20, 466-505. http://dx.doi.org/10.2307/2406585

Loudon, A. S. I. (1994). Photoperiod and the regulation of annual and circannual cycles of food intake. Proceedings of the Nutrition Society, 53, 495-507. http://dx.doi.org/10.1079/PNS19940060

Lowe, C. F., \& Harzem, P. (1977). Species differences in temporal control of behavior. Journal of the Experimental Analysis of Behavior, 28, 189-201. http://dx.doi.org/10.1901/jeab.1977.28-189

Lowe, C. F., Harzem, P., \& Spencer, P. T. (1979). Temporal control of behavior and the power law. Journal of the Experimental Analysis of Behavior, 31, 333-343. http://dx.doi.org/10.1901/jeab.1979.31-333

Machado, A. (1997). Learning the temporal dynamics of behavior. Psychological Review, 104, 241-265. http://dx.doi.org/10.1037/0033-295X.104.2.241

Machado, A., \& Cevik M. (1998). Acquisition and extinction under periodic reinforcement. Behavioural Processes, 44,237-262. http://dx.doi.org/10.1016/ S0376-6357(98)00052-7

Machado, A., \& Keen, R. (1999). Learning-to-time (LeT) or scalar expectancy theory (SET)? A critical test of two models of timing. Psychological Science, 10, 285-290. http://dx.doi.org/10.1111/14679280.00152

Machado, A., Malheiro, M. T., \& Erlhagen, W. (2009). Learning to time: A perspective. Journal of the Experimental Analysis of Behavior, 92, 423-458. http://dx.doi.org/10.1901/jeab.2009.92-423

Machado, A., \& Oliveira, L. (2009). Dupla bissecção temporal: Testes críticos de dois modelos de timing
[Double temporal bisection: Critical tests two timing models]. Acta Comportamentalia, 17, 25-60.

Machado, A., \& Pata, P. (2005). Testing the scalar expectancy theory (SET) and the learning-to-time model (LeT) in a double bisection task. Learning and Behavior, 33, 111-122. http://dx.doi.org/10.3758/ BF03196055

Marler, P., \& Tamura, M. (1964). Culturally transmitted patterns of vocal behavior in sparrows. Science, 146, 1483-1486. http://dx.doi.org/10.1126/ science.146.3650.1483

Martinet, L., Mondain-Monval, M., \& Monnerie, R. (1992). Endogenous circannual rhythms and photorefractoriness of testis activity moult and prolactin concentrations in mink (Mustela vison). Journal of Reproduction and Fertility, 95, 325-338. http://dx.doi.org/10.1530/jrf.0.0950325

Massin, M. M., Maeyns, K., Withofs, N., Ravet, F., \& Gérard, P. (2000). Circadian rhythm of heart rate and heart rate variability. Archives of Disease in Childhood, 83, 179-182. http://dx.doi.org/10.1136/ adc.83.2.179

McNamara, J.M. \& Houston, A. I. (1985). Optimal foraging and learning. Journal of Theoretical Biology, 117, 23,1-249. http://dx.doi.org/10.1016/S00225193(85)80219-8

Mistlberger, R. E., \& Skene, D. J. (2004). Social influences on mammalian circadian rhythms: Animal and human studies. Biological Reviews of the Cambridge Philosophical Society, 79, 533-556. http://dx.doi.org/10.1017/S1464793103006353

Monteiro, T., \& Machado, A. (2009). Oscillations following periodic reinforcement. Behavioural Processes, 81, 170-188. http://dx.doi.org/10.1016/j. beproc.2008.10.003

Nisimura, T., \& Numata, H. (2001). Endogenous timing mechanism controlling the circannual pupation rhythm of the varied carpet beetle Anthrenus verbasci. Journal of Comparative Physiology. A, Sensory, Neural, and Behavioral Physiology, 187, 433-440. http://dx.doi.org/10.1007/s003590100215

Oliveira, L., \& Machado, A. (2008). The effect of sample duration and cue on a double temporal discrimination. Learning and Motivation, 39, 71-94. http://dx.doi.org/10.1016/j.lmot.2007.06.001

Oliveira, L., \& Machado, A. (2009). Context effect in a temporal bisection task with the choice keys available during the sample. Behavioural Processes, 81, 286-292. http://dx.doi.org/10.1016/j. beproc.2008.12.021

Pahl, M., Zhu, H., Pix, W., Tautz, J., \& Zhang, S. (2007). Circadian timed episodic-like memory-A bee knows what to do when, and also where. Journal of Experimental Biology, 210, 3559-3567. http://dx.doi.org/10.1242/jeb.005488 
Panda, S., Hogenesch, J. B., \& Kay, S. A. (2002). Circadian rhythms from flies to human. Nature, 417, 329-335. http://dx.doi.org/10.1038/417329a

Parker, G. A., \& Stuart, R. A. (1976). Animal behavior as a strategy optimizer: Evolution of resource assessment strategies and optimal emigration thresholds. American Naturalist, 110, 1055-1076. http://dx.doi.org/10.1086/283126

Pavlov, I. P. (1927). Conditioned reflexes. Oxford, England: Oxford University Press.

Pengelley, E. T., \& Asmundson, S. J. (1974). Circannual rhythmicity in hibernating mammals. In E. T. Pengelley (Ed.), Circannual clocks: Annual biological rhythms (pp. 95-160). New York, NY: Academic Press.

Pizzo, M. J., \& Crystal, J. D. (2002). Representation of time in time-place learning. Animal Learning and Behavior, 30, 387-393. http://dx.doi.org/10.3758/ BF03195963

Platt, J. R., \& Davis, E. R. (1983). Bisection of temporal intervals by pigeons. Journal of Experimental Psychology: Animal Behavior Processes, 9, 160-170. http://dx.doi.org/10.1037/0097-7403.9.2.160

Rebar, D., Bailey, N. W., \& Zuk, M. (2009). Courtship song's role during female mate choice in the field cricket Teleogryllus oceanicus. Behavioral Ecology, 20, 1307-1314. http://dx.doi.org/10.1093/beheco/arp143

Refinetti, R., \& Menaker, M. (1992). The circadian rhythm of body temperature. Physiology and Behavior, 51, 613-637. http://dx.doi.org/10.1016/00319384(92)90188-8

Reppert, S. M., \& Weaver, D. R. (2002). Coordination of circadian timing in mammals. Nature, 418, 935-941. http://dx.doi.org/10.1038/nature00965

Richelle, M., \& Lejeune, H. (1980). Time in animal behavior. New York, NY: Pergamon.

Rijnsdorp, A., Daan, S., \& Dijkstra, C. (1981). Hunting in the kestrel, Falco tinnunculus, and the adaptive significance of daily habits. Oecologia, 50, 391-406. http://dx.doi.org/10.1007/BF00344982

Roberts, S. (1981). Isolation of an internal clock. Journal of Experimental Psychology: Animal Behavior Processes, 7, 242-268. http://dx.doi.org/10.1037/00977403.7 .3 .242

Roberts, S. (1998). The mental representation of time: Uncovering a biological clock. In D. Scarborough \& S. Sternberg (Eds.), An invitation to cognitive science: Methods, models, and conceptual issues (2nd ed., Vol. 4, pp. 53-106). Cambridge, MA: MIT Press.

Roberts, W. A., Cheng, K., \& Cohen, J. S. (1989). Timing light and tone signals in pigeons. Journal of Experimental Psychology: Animal Behavior Processes, 15, 23-35. http://dx.doi.org/10.1037/00977403.15.1.23
Russell, R., \& Kirkpatrick, K. (2007). The role of temporal generalization in a temporal discrimination task. Behavioural Processes, 74, 115-125. http://dx.doi.org/10.1016/j.beproc.2006.08.004

Saksida, L. M., \& Wilkie, D. M. (1994). Time-of-day discrimination by pigeons, Columba livia. Animal Learning and Behavior, 22, 143-154. http://dx.doi. org/10.3758/BF03199914

Schneider, B. A. (1969). A two-state analysis of fixedinterval responding in the pigeon. Journal of the Experimental Analysis of Behavior, 12, 677-687. http://dx.doi.org/10.1901/jeab.1969.12-677

Siegel, S. F. (1986). A test of the similarify rule model of temporal bisection. Learning and Motivation, 17, 59-75. http://dx.doi.org/10.1016/00239690(86)90020-2

Staddon, J. E. R., \& Cerutti, D. T. (2003). Operant conditioning. Annual Review of Psychology, 54, 115-144. http://dx.dei.org/10.1146/annurev. psych.54.101601.145124

Staddon, J. E. R., \& Higa, J. J. (1991). Temporal learning. In G. Bower (Ed.), The psychology of learning and motivation (Vol. 27, pp. 265-294). New York, NY: Academic Press.

Staddon, J. E. R., \& Higa, J. J. (1999). Time and memory: Towards a pacemaker-free theory of interval timing. Journal of the Experimental Analysis of Behavior, 71, 215-251. http://dx.doi.org/10.1901/ jeab.1999.71-215

Stein, H. (1951). Untersuchungen über den Zeitsinn bei Vögeln [Studies on the time sense in birds]. Zeitschrift fur Vergleichende Physiologie, 33, 387-403.

Stephens, D. W., \& Krebs, J. R. (1986). Foraging theory. Princeton, NJ: Princeton University Press.

Stubbs, D. A. (1976). Response bias and the discrimination of stimulus duration. Journal of the Experimental Analysis of Behavior, 25, 243-250. http://dx.doi.org/10.1901/jeab.1976.25-243

Thorpe, C. M., Hallett, D., \& Wilkie, D. M. (2007). The role of spatial and temporal information in learning interval time-place tasks. Behavioural Processes, 75, 55-65. http://dx.doi.org/10.1016/j. beproc.2007.01.002

Thorpe, C. M., \& Wilkie, D. M. (2005). Interval timeplace learning by rats: Varying reinforcement contingencies. Behavioural Processes, 70, 156-167. http://dx.doi.org/10.1016/j.beproc.2005.06.005

Thorpe, C. M., \& Wilkie, D. M. (2006). Properties of time-place learning. In E. A. Wasserman \& T. R. Zentall (Eds.), Comparative cognition: Experimental explorations of animal intelligence (pp. 229-245). New York, NY: Oxford University Press.

Vieira de Castro, A. C., \& Machado, A. (2012). The interaction of temporal generalization gradients predicts 
the context effect. Journal of the Experimental Analysis of Behavior, 97, 263-279. http://dx.doi.org/10.1901/ jeab.2012.97-263

Vieira de Castro, A. C., Machado, A., \& Tomanari, G. Y. (2013). The context effect as interaction of temporal generalization gradients: Testing the fundamental assumptions of the learning-to-time model. Behavioural Processes, 95, 18-30. http://dx.doi. org/10.1016/j.beproc.2013.01.007

Wahl, O. (1932). Neue Untersuchungen über das Zeitgedächtnis der Bienen [New studies on the term memory of bees]. Zeitschrift für Vergleichende Physiologie, 16, 529-589.

Wearden, J. H. (1999). "Beyond the fields we know ...": Exploring and developing scalar timing theory. Behavioural Processes, 45, 3-21. http://dx.doi. org/10.1016/S0376-6357(99)00006-6

Wenger, D., Biebach, H., \& Krebs, J. R. (1991). Freerunning circadian rhythm of a learned feeding pattern in starlings. Naturwissenschaften, 78, 87-89. http://dx.doi.org/10.1007/BF01206266

Whitaker, S., Lowe, C. F., \& Wearden, J. H. (2003). Multiple-interval timing in rats: Performance on two-valued mixed fixed-interval schedules. Journal of Experimental Psychology: Animal Behavior Processes, 29, 277-291. http://dx.doi.org/10.1037/00977403.29.4.277
Whitaker, S., Lowe, C. F., \& Wearden, J. H. (2008). When to respond? And how much? Temporal control and response output on mixed-fixed-interval schedules with unequally probable components. Behavioural Processes, 77, 33-42. http://dx.doi.org/10.1016/j. beproc. 2007.06 .001

Wilkie, D. M., Saksida, L. M., Samson, P., \& Lee, A. (1994). Properties of time-place learning by pigeons, Columba livia. Behavioural Processes, 31, 39-56. http://dx.doi.org/10.1016/0376-6357(94)90036-1

Williams, K. S., \& Simon, C. (1995). The ecology, behavior, and evolution of periodical cicadas. Annual Review of Entomology, 40, 269-295. http://dx doi. org/10.1146/annurev.en.40.010195.001413

Wynne, C. D. L., \& Staddon, J. E. R. (1988). Typical delay determines waiting time on periodic-food schedules: Static and dynamic tests. Journal of the Experimental Analysis of Behavior, 50, 197-210. http://dx.doi.org/10.1901/jeab.1988.50-197

Zeiler, M. D., \& Powell,D. G. (1994). Temporal control in fixed-interval schedules. Journal of the ExperimentalAnalysis of Behavior, 61, 1-9. http:// dx.doi.org/10.1901/jeab.1994.61-1

Zucker, I. (2001). Circannual rhythms: Mammals. In J.S. Takahashi, F. W. Turek, \& R. Y. Moore (EdS.), Handbook of behavioral neurobiology: Vol. 12. Circadian clocks (pp. 509-528). New York, NY: Kluwer Academic/Plenum. 